Final Report for NYSERDA Under Agreements No. 20756 and 18543

\title{
Long-term Energy and Emissions Savings Potential in New York City Buildings
}

\author{
Vatsal Bhatt and John Lee \\ Brookhaven National Laboratory \\ Yehuda Klein, Hildegaard Link and José Pillich \\ City University of New York
}

Submitted to: New York State Energy Research and Development Authority

Liz Hanna, Project Manager

Under EPA Grant NP-97227609-0

Alex Peck, Project Officer

Edward J. Linky, Project Advisor

September 30, 2012

Notice: This manuscript has been authored by employees of Brookhaven Science Associates, LLC under Contract No. DE-AC02-98CH10886 with the U.S. Department of Energy. The publisher by accepting the manuscript for publication acknowledges that the United States Government retains a non-exclusive, paid-up, irrevocable, world-wide license to publish or reproduce the published form of this manuscript, or allow 


\section{Notice}

This report was prepared by Brookhaven National Laboratory and the City University of New York in the course of performing work contracted for and sponsored by the New York State Energy Research and Development Authority. The opinions expressed in this report do not necessarily reflect those of the State of New York, and reference to any specific product, service, process, or method does not constitute an implied or expressed recommendation or endorsement of it. Further, the State of New York makes no warranties or representations, expressed or implied, as to the fitness for particular purpose or merchantability of any product, apparatus, or service, or the usefulness, completeness, or accuracy of any processes, methods, or other information contained, described, disclosed, or referred to in this report. The State of New York and the contractor make no representation that the use of any product, apparatus, process, method, or other information will not infringe privately owned rights and will assume no liability for any loss, injury, or damage resulting from, or occurring in connection with, the use of information contained, described, disclosed, or referred to in this report.

\section{Acknowledgements}

The authors would sincerely like to thank management and colleagues of the Brookhaven National Laboratory (BNL) and the City University of New York (CUNY) for supporting this project. We greatly appreciate support and direction offered by the New York State Energy Research and Development Authority (NYSERDA) towards planning and execution of this project, especially project managers Elizabeth Hanna and Peter Savio. We sincerely acknowledge the program manager Alex Peck and the project advisor Edward Linky of the Environmental Protection Agency - Region II for providing Pollution Prevention grant and offering unyielding support for this project. We hope this project report delivers measurable results for Pollution Prevention and outlines clear strategy and matrix for targeted outreach to stakeholders.

\section{Brief Outline of the Project}

The New York State Energy Research and Development Authority (NYSERDA) partnered with the Brookhaven National Laboratory (BNL) and the City University of New York (CUNY) to develop an integrated methodology that is capable of quantifying the impact of energy efficiency and load management options in buildings, including CUNY's campus buildings, housing projects, hospitals, and hotels, while capturing the synergies and offsets in a complex and integrated energy-environmental system. The results of this work serve as a guideline in implementing urban energy efficiency and other forms of urban environmental improvement through cost-effective planning at the institutional and local level. 


\section{Table of Contents}

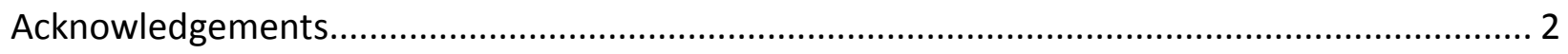

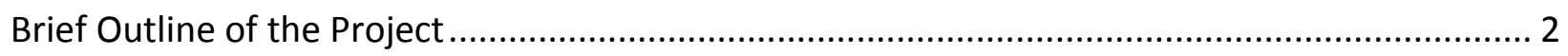

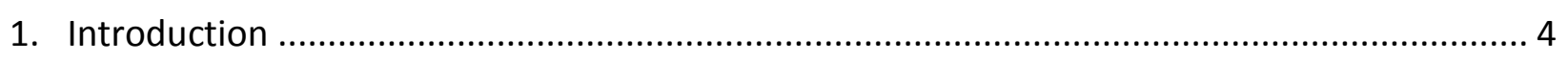

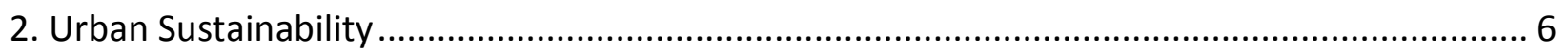

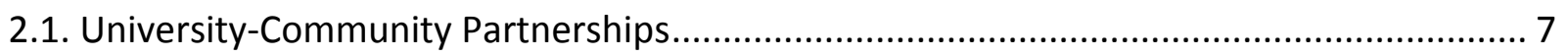

2.2. Local Governance - Community Planning Boards ........................................................ 9

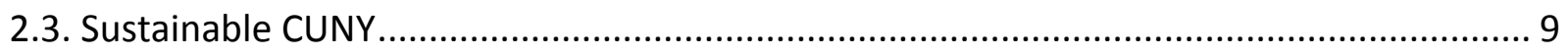

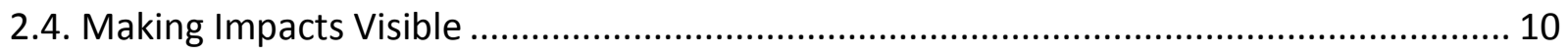

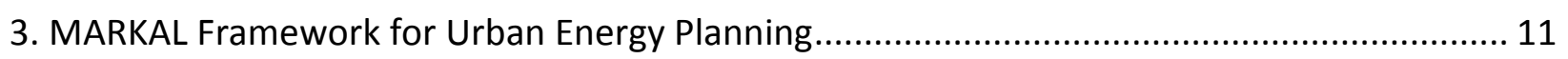

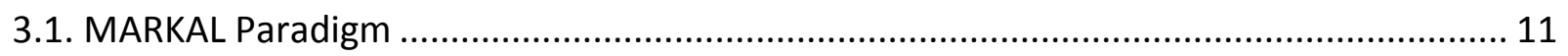

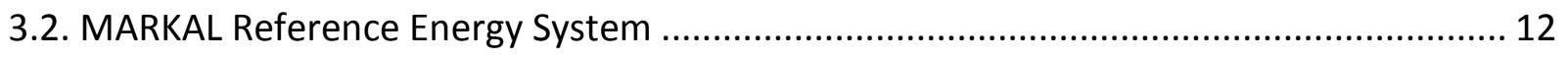

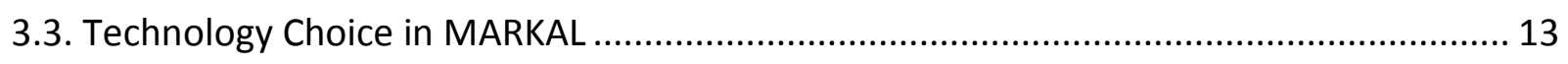

3.4. Customizing MARKAL for New York City Case Study ..................................................... 14

4. Campus-Neighborhood Partnerships ............................................................................... 17

4.1. Case Study I: CCNY and Manhattan Community Board 9......................................... 18

4.2. Shared Goals: CCNY and Community Planning Board 9 ............................................. 18

4.3. MARKAL Analysis for Buildings Energy Conservation \& Efficiency-CB9 …....................... 19

4.4. The Environmental Impacts of Green Technologies at CCNY .......................................... 23

4.5. Estimating Green Roof Associated Reduction of Electric Load ........................................ 25

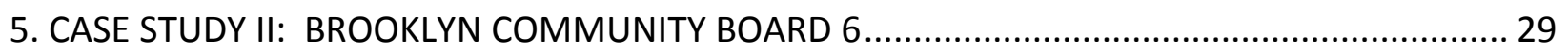

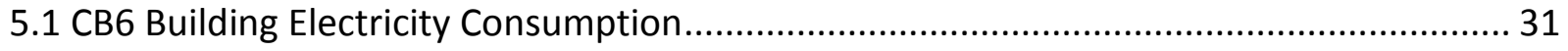

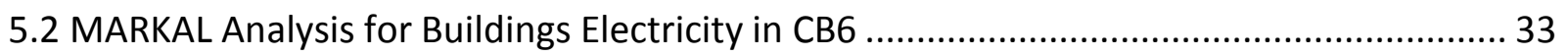

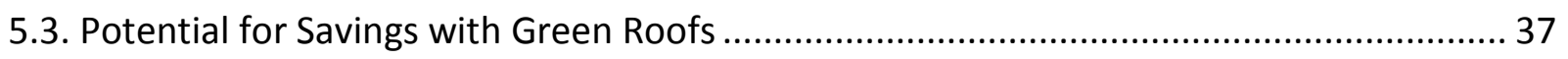

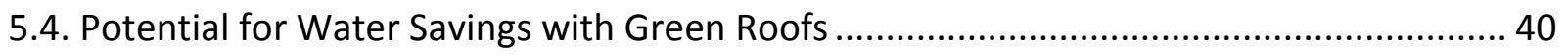

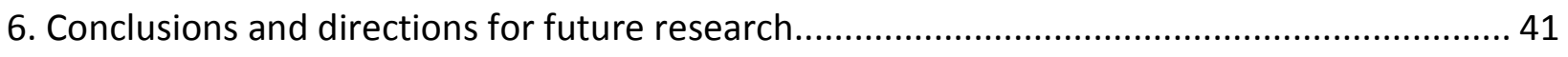

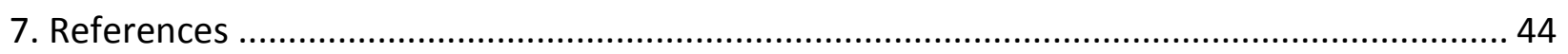




\section{Introduction}

The Brookhaven National Laboratory (BNL) and the City University of New York (CUNY) utilized the government, research and academia collaborative to develop a diversified energy analysis portfolio, improve market mechanisms, and facilitate the introduction and adoption of advanced energy efficient technologies that will help New Yorkers plan for and respond to uncertainties in the energy supply, conserve energy, reduce emissions and improve public health. This final report sent to NYSERDA, for a final submission towards EPA-Region 2 grant addresses reductions in electricity use and greenhouse gas emission in the strategic locales (Community Boards 6 and 9) within New York City that offer opportunities for electricity load management strategies and energy conservation programs and policies; and the need to explore both direct and indirect contributions of energy/electricity conservation policies such as Energy Star intended to mitigate the impact of environmental emissions resulting from energy use in electricity generation. The Brookhaven National Laboratory (BNL) and the City University of New York (CUNY) partnered seamlessly to enhance the technical capability and community outreach.

To tackle these complex interactions between electricity supply-demand and environmental issues requires application of a robust analytic approach that comprehensively addresses energy and environment concerns. The basis of this approach used here is an integrated energy assessment tool centered on an extended and updated version of the New York City MARKAL model (NYC-MARKAL).

The existing NYC-MARKAL was built by BNL with the help of a Pollution Prevention Grant from the Environmental Protection Agency (EPA) to evaluate mitigation measures for peak-load reduction and easing the "urban heat island" effect in a Lower Manhattan case-study, and to assess impacts of these policies in reducing electricity peak, annual demand and emissions over the long-term (2000-2025) (Linky et al., 2008).

This project expanded the NYC-MARKAL model and used it to examine alternative strategies of implementing green technologies in selected case studies of CUNY's campus buildings, housing projects, hospitals, and hotels that are recognized by the EPA Energy Star Buildings Program and EPA Portfolio Manager. The demand module of the model simulates the "business as usual" electricity demand by end-use in these building space types. Altered demand patterns attributable to efficiency programs (e.g., Energy Star), load management, conservation, and building codes are generated to compare with "business as usual". This is accomplished by measuring their difference in electricity use and power load at the sub-station level which is a part of the MARKAL model solution. The differences in sub-station data feed into the entire power network supply New York City to generate the impact of programs and measures on fuel use, greenhouse gas (GHG) and criteria pollutant emissions at specific power 
plants, as well as energy system costs and future expansion plans for electricity generation for the long-term (2010-2030).

"The City University of New York (CUNY) is dedicated to minimizing its ecological impact and promoting a culture of sustainability throughout our community." ${ }^{1}$ An additional objective of this study is to examine the CUNY Sustainability Initiative in the broader context of efforts by colleges and universities to act as agents of positive social change within their communities. The CUNY Sustainability Initiative is a university-wide effort addressing a wide range of environmental issues with a special focus on carbon footprint reduction. Sustainable CUNY is a commitment that was undertaken by Chancellor Matthew Goldstein on June 6, 2007 when he publicly accepted the challenge issued by Mayor Bloomberg for colleges and universities in New York to reduce our carbon footprint by $30 \%$ by the PlaNYC early implementation target date of 2017 (NYC, 2007). The CUNY Sustainability Initiative reaches beyond the campus boundaries to address the city-wide goals of PlaNYC 2030 (NYC, 2007). Inherent in the claim of "...promoting sustainability throughout our community" is the notion of a genuine community-university partnership in which all members are equally involved from the outset in determining the issues to be dealt with and in developing plans of action that will be of mutual benefit to all.

The Sustainable CUNY initiatives are in response to the goals of PlaNYC 2030, and span CUNY instructional, research and operational activities. A pilot project to assess the environmental impacts of campus operations for City College (CCNY) was recently completed as a part of the Greenhouse Gas (GHG) Inventory Program. ${ }^{2}$ This study provides both energy demand and emissions data as well as proposed adaptation strategies. Working within the framework of the CUNY Sustainability Initiative, we developed an energy data framework for additional pilot campuses within the CUNY system of nineteen campuses with just under three hundred buildings and 20 million square feet of floor area. The framework will be tested and made available to facilitate energy planning for other campuses.

The highly disaggregated, transparent, and transferable nature of the MARKAL model allows local governance (e.g., Community Planning Boards), utilities (e.g., ConEdison, New York Power Authority), project stakeholders (e.g., Office of Design, Construction and Management, or the NYC Dormitory Authority), and the general public (e.g., building managers) to apply its output for promoting on a voluntary basis or in a regulatory manner energy efficiency in existing buildings and in new building designs. The flexibility of the model structure and interactive data management enable MARKAL to facilitate analysis under changing conditions (e.g., projected energy prices) and regulations (e.g., carbon cap). This allows long-term

\footnotetext{
${ }^{1}$ This statement, attributed to the CUNY Sustainability website, is widely quoted. See, for example, T. S. Johnson, 2009, "CUNY Sustainability Contest," the Kingsborough Scepter online edition, March, 2009, http://www1.kingsborough.edu/aboutkcc/scepter/archived/mr09_sustain.html

${ }^{2}$ Sinha, P. and Spiegel, S., 2008. Greenhouse Gas (GHG) Inventory Program, Prepared for City College of New York, (CCNY), by O'Brien and Gere, Blue Bell, PA.
} 
monitoring and tracking of the performance in the study area EPA Programs such as Energy Star Buildings, Combined Heat and Power Partnership, and Green Power Partnership.

\section{Urban Sustainability}

Urban sustainability involves three related elements: economic development, environmental sustainability, and social justice. Hamstead and Quinn (2005) argue for an ecological sensibility that embeds, within the framework of community development, a sensitivity to the limits to economic growth imposed by limited natural resources, as well as social justice and intergenerational equity. The authors outline a series of increasingly broad conceptions of the notion of economic development: the perspectives of neoclassical economics; environmental economics, and ecological economics. The standard neoclassical model addresses the question of economic efficiency - the optimal allocation of scarce resources among competing uses. Environmental economics explicitly addresses environmental and natural resource externalities - market failures that arise from the failure to correctly account for the depletion of natural resources or the environmental damages created by economic activities. The authors challenge the adequacy of environmental economics to properly address the exigencies of sustainable development. They contrast both the neoclassical and environmental economic perspectives with that of ecological economics. The authors attribute to the latter model these guiding principles: 1 , it rejects economic growth as the primary desideratum; 2 , it balances economic, social and ecological concerns in decisionmaking; 3 , it is concerned first with the appropriate scale of economic activity, second with distributional equity, and last with economic efficiency; and 4, it seeks to balance human and non-human access to scarce resources.

The Local Agenda 21 process, stimulated by the 1992 Earth Summit in Rio, is an effort to develop community-based environmental sustainability initiatives (see Sharp, 2002). Selman and Parker (1999) assesses the effectiveness of Local Agenda 21 to engage stakeholders in the process of sustainable community development in the U.K. In a detailed case study of efforts to implement Local Agenda 21, the authors identify a number of recurrent themes. These include the effort to "mesh the top-down organizational delivery side (having a fairly widely agreed vision of the city) with community led action (making the vision happen)." In exploring the narratives of sustainable community development, Selman and Parker identify the tensions that arise in the effort to empower communities while maintaining the cooperation of economic and political elites.

Hess and Winner (2007) review thirty case studies of sustainable community development in the United States. The studies span a wide range of sustainability projects, 
including community gardens, green transportation and electricity, and the reuse and recycling of waste. The authors use these case studies to explore the interdependent goals of economic development, environmental sustainability and social justice. They conclude that "there are affordable ways to address goals of enhanced environmental sustainability as well as community development goals of job creation and improvement in the lives of low-income members of a community."

Urban sustainability is an appropriate focus for university-community engagement, as it addresses issues of substantive concern to both the university and the community, and enables faculty and students to draw on their areas of expertise to empower the community. Parker and Selman (1997) explore in detail three "sustainable development" initiatives in Canada that parallel the Local 21 Agenda projects in the U.K. Of particular relevance to the CUNY Sustainability effort are two projects at the University of British Columbia in which the academic community developed both policy-relevant analytical tools and a broadly-based town-gown partnership, the "Task Force on Planning Healthy and Sustainable Communities." The Task Force was an effort by the academic community to "reconnect action and consequence in the consciousness of the individual and the community." This effort proceeded from the perception that it was necessary to bridge the gap between academic theory and practice. The first project entailed the development of quantitative measures of "ecological footprint" (EF) with graphical tools designed to represent the environmental consequences of different lifestyle choices. The second project utilized EF tools in municipal planning in the City of Richmond, a community of 130,000 located on an island in the Fraser river delta, south of downtown Vancouver. The Task Force chose the term "Social Caring Capacity" to reflect the goals of individual health, community health and ecosystem health. The implementation of sustainable community goals was addressed by a symposium that engaged a wide range of participants, from academics and community activists to politicians and planners. Ultimately, however, the local government rejected Task Force recommendations, due in part to the lack of local resources and commitment to the goal of sustainability, and the difficulty in translating academic models into policy-relevant language.

\subsection{University-Community Partnerships}

Historically, the "town and gown" relationship between universities and their local communities has not been easy. There are many reasons for the difficulties including the fact that educational institutions are tax exempt and are not obligated to pay into the municipalities where they are rooted and where their students are users of goods and services. There is an ongoing debate about whether universities are more of an economic resource or drain to their local economies (Baker-Minkel, 2004). On the one hand universities increase cultural and educational opportunities, on the other they may not provide any fiscal benefit to their city 
budget and in turn be regarded as a drain on the system. While universities may be seen as financial drains on the greater system, they are also seen as culturally diverse with many opportunities for cultural enrichment to their surrounding communities (Bromley, 2006). Students are seen by local residents as a nuisance, as people who are not concerned with the overall well-being of the communities in which they reside. University towns are generally regarded to have transient populations that do not stay in the area long enough to become civically involved citizens with a desire to make the community better.

Martin, et al. (2005) provides three important observations about what is necessary for the success of innovative university-community partnerships. First, partnerships focusing on social problems require synergistic collaboration to increase the potential impact of policies. Second, although research is in the developmental stage, the existing research has been guided by the governance paradigm shift in public administration which provides theoretical justification for the importance of multiple stakeholders in the process of this collaborative work. Third, key to the concept of university-community partnerships is the notion of innovative programs and policies which are produced through synergistic relationships with the stakeholders.

Reardon (2006) characterizes the current trend toward university engagement with the surrounding communities as a response to the deindustrialization, suburbanization, and disinvestment that has left much of the urban core decayed and impoverished. He examined in detail the nature and outcomes associated with some ten community/university partnerships, and identified the economic and political forces that led to their creation, the barriers that were overcome in achieving effective town-gown partnerships, and the pre-requisites for effective collaboration. Reardon notes that, in each case, town-gown partnerships engaged both politically and economically privileged and marginalized elements within the local communities. It was necessary to address the suspicions of low-income communities and communities of color who are used to being the objects of academic study, rather than full partners in community development projects. On the other hand, academics needed to move out of their comfort zone, within the realm of positivist-oriented scholarship, and engage in participant action research which is sensitive to the research outcomes.

Weinberg (2002) poses two crucial questions: "Can universities be agents of progressive social change? How would we know if a university was acting as an agent of social change?" Weinberg characterizes a traditional approach to town-gown relationships as being based primarily on the institutional needs of the academic institution. Although social change may occur, this is typically an unintended consequence of an activity that is undertaken to realize other objectives. The primary goals of town-gown engagement might include providing educational opportunities to students, with incidental provision of services to neighborhood residents, or neighborhood improvement, in order to make the campus surroundings more 
attractive for current and prospective students. In either event, benefits to the community are incidental to the core mission of the university. Weinberg explores in detail four case studies, Loyola University (Chicago, IL), Trinity College (Hartford, CT), Colgate University (Hamilton, NY), and Georgetown University (Washington, D.C.) in which the university uses its academic, financial, or political resources as explicit agents of progressive social change. Particular projects are undertaken not only to provide educational opportunities to students and community services, but to empower the community, by giving them tools they can subsequently use for political engagement.

\subsection{Local Governance - Community Planning Boards}

Our work is focused on developing tools; methods and processes scalable from campus to the local community. Building tools to be shared from campus to campus creating local initiatives and circles of involvement around each CUNY campus is an essential outcome of this endeavor. Bromely (2006) suggests the importance of "seeding ideas into the local arena - ideas which may be taken up and championed by others". Environmental justice is one of the project focuses, which is defined as the equal protection and meaningful involvement of all people with respect to the development, implementation, and enforcement of environmental laws, regulations, and policies and the equitable distribution of environmental benefits (Agyeman, Bullard and Evans, 2002.)

Community-university partnerships have been effective in addressing a variety of social problems. We believe that environmental sustainability is a pressure point where partnerships at the community-university scale can drive implementation of the existing sustainability agenda in NYC deep into the "neighborhoods". The long-term vision of productive working relationships between CUNY campuses and their host community planning boards has spurred this project from its inception.

\subsection{Sustainable CUNY}

The City University of New York is the nation's largest urban public university. Founded in New York City in 1847 as the Free Academy, CUNY's 19 campuses serve more than 231,000 degree-credit students and 230,000 adult, continuing and professional education students. The objective of this study is to show how the university can function as a resource for surrounding neighborhoods. With the wide geographic dispersion of campus locations throughout the five boroughs, CUNY has the potential to become a positive presence and reciprocal partner in community endeavors.

This project is based in part on a framework developed by the University of British Columbia. In this report, we discuss the elements of this project: first, the development of analytical tools to assess campus and neighborhood-scale environmental impacts; and second 
the use of these tools in a town-gown partnership designed to further the interests of all stakeholders (See Parker and Selman, 1997).

In the broader context of NYC as a healthy and sustainable city this project aims to serve as a model to improve environmental standards and reducing greenhouse gas emissions while fitting in with the social, economic, and political goals of sustainable development. This project adheres to two broad categories of environmental action within which it is suggested that the performance of all cities should be assessed (Satterthwaite, 1997). The first is "minimizing the transfer of environmental costs to the inhabitants and ecosystems surrounding the city" and the second is "ensuring progress towards what is often termed 'sustainable consumption'- i.e. ensuring that the goods and services required to meet everyone's consumption needs are delivered without undermining the environmental capital of nations and the world" (Satterthwaite,1997).

\subsection{Making Impacts Visible}

At the urban and neighborhood scale, electricity and fuel demands by CUNY have impacts on air quality, public health, and reliability of the local electricity grid. The development of community-university partnerships presupposes an effort to acknowledge and mitigate any adverse environmental or public health impacts of campus operations at both neighborhood and urban scales. These impacts include:

- Fuel choices by CUNY entail local emissions of nitrogen oxide and volatile organic compounds (VOCs), precursors to ground-level ozone. These emissions have been associated with an increased incidence of chronic illnesses (Markandya and Wilkinson, 2007; Jacobson, 2008; Wilkinson, Smith, Joffe, and Haines, 2007).

- Peak electricity demands require in-city generation that may contribute to smog conditions and respiratory distress. The New York City system peak tends to occur on hot summer weekday afternoons, which are often "ozone alert" days. These emissions particularly affect vulnerable populations - the elderly, the very young, and asthma sufferers.

- Peak demands may stress local electrical distribution networks, reducing electrical reliability. Extreme temperatures and consequent electricity blackouts or brownouts create an environment with increased vulnerability to the effects of heat and heatrelated illness and death. Strategies to mitigate peak demands (demand side management, load shedding) thus have beneficial impacts not only on system reliability but also on public health. 


\section{MARKAL Framework for Urban Energy Planning}

This project uses an integrated energy planning methodology, MARKAL, to design optimal strategies for long-term energy security, climate change mitigation and environmental sustainability for rapidly growing urban areas, applied to a specific city case study (e.g.: New York City). The methodology comprehensively evaluates costs and benefits of alternative technology and resource use options to aid effective decision making. It identifies interdependencies of various energy sub-systems (including energy supply, production, distribution and consumption technologies and alternatives) and comprehensively analyzes the behavior of the entire energy system for long-term planning.

\subsection{MARKAL Paradigm}

MARKAL (acronym for MARKet ALlocation) is a mathematical model for local, national or multi-regional energy systems, which provides a technology-rich basis for estimating energy dynamics over a long-term, multi-period time horizon. MARKAL was developed at BNL after the oil embargo in the 1970s, in collaboration with the US Department of Energy (USDOE) and the International Energy Agency (IEA). Since then it has been enhanced, updated, verified and validated by a user community under the aegis of the Energy Technology Systems Analysis Program (www.etsap.org) of IEA.

MARKAL provides a framework to evaluate all resource and technology options within the context of the entire energy/materials system, and captures the market interaction among fuels to meet demands (e.g., competition between gas and coal for electric generation). The model explicitly tracks the vintage structure of all capital stock in the economy that produces, transports, transforms, or uses energy and the associated materials. ${ }^{3}$

The MARKAL energy economy is made up of producers and consumers of energy carriers. MARKAL, like most computable economic equilibrium models, assumes perfectly competitive markets for energy carriers-producers maximize profits and consumers maximize their collective utility. The result is a supply-demand equilibrium that maximizes the net total surplus (i.e. the sum of producers' and consumers' surpluses). MARKAL may, however, depart from perfectly competitive market assumptions by the introduction of user-defined, explicit special assumptions, such as limits to technological penetration, speed of introduction of new technologies, technology-specific discount rates, etc. Operationally, a MARKAL run configures the energy system (of a set of regions) over a certain time horizon in such a way as to minimize the net total cost (or equivalently maximize the net total surplus) of the system, while satisfying a number of constraints. MARKAL is generally run in a dynamic manner, which is to say that all

\footnotetext{
${ }^{3}$ Hamilton, L., G. Goldstein, J. Lee, A. Manne, W. Marcuse, S. Morris, and C. Wene (1992). MARKAL-MACRO: An Overview. Brookhaven National Laboratory. Report BNL-48377
} 
investment decisions are made in each period with full knowledge of future events (often referred to as perfect foresight). ${ }^{4}$

\subsection{MARKAL Reference Energy System}

In MARKAL, the entire energy system is represented as a network, based on the Reference Energy System (RES) concept. The RES depicts all possible flows of energy from resource extraction, through energy transformation, distribution, and transportation, to enduse devices that satisfy the demands of useful energy services (e.g., ton in cooling, lumensecond in lighting). Figure 1 illustrates a simplified RES in graphical form. The MARKAL model has detailed technical representations of four end-use sectors (residential, commercial, industrial, and transportation), as well as fossil fuel and renewable resources, power generation, hydrogen production, and other intermediate conversion sectors (Ibid Hamilton et al, 1992).

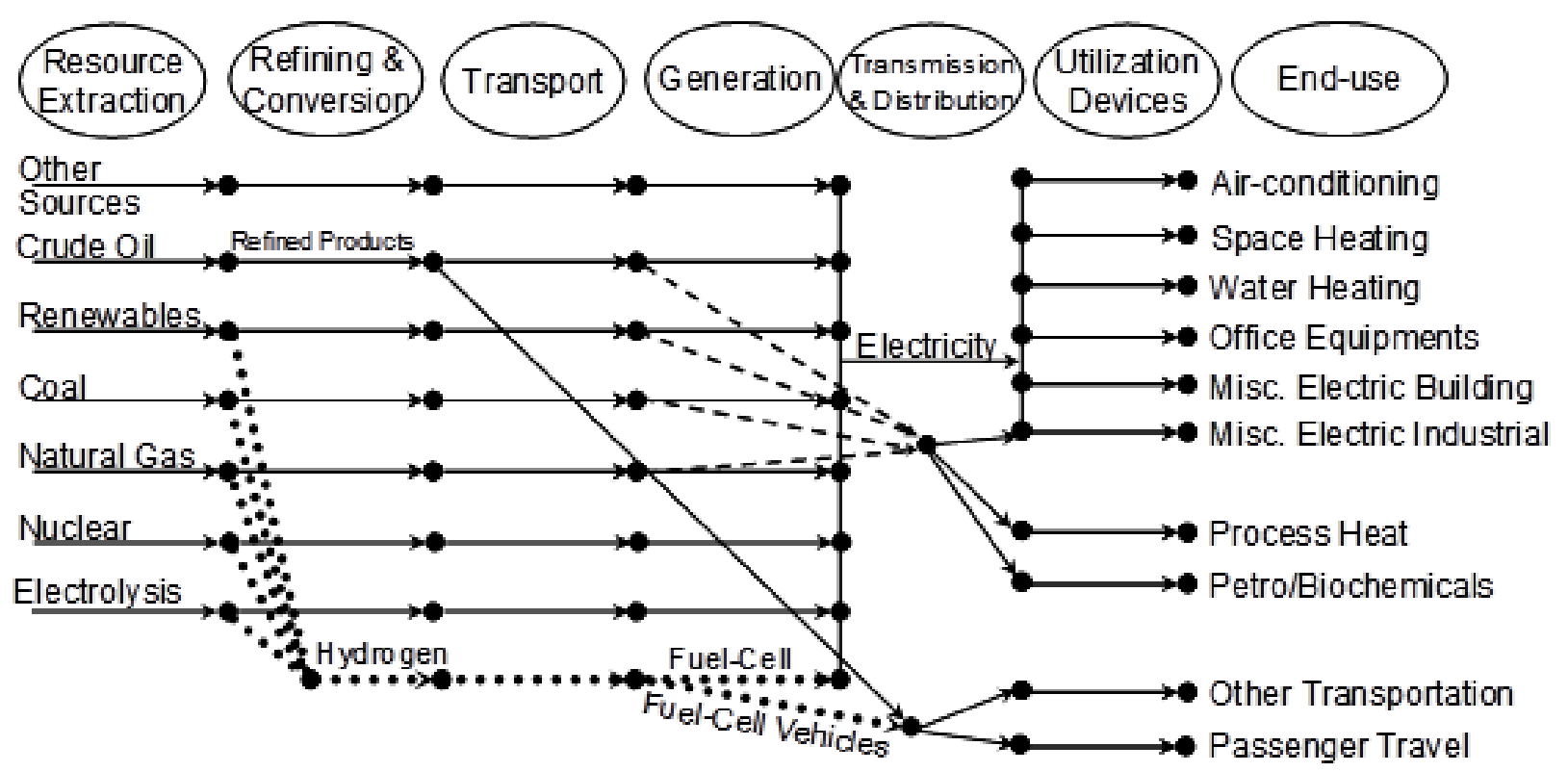

Figure 1: MARKAL Reference energy system. Source: Bhatt, $2010^{5}$

\footnotetext{
${ }^{4}$ Loulou, R., G. Goldstein, K. Noble (2004). Documentation for the MARKAL Family of Models. Available from Energy Technology Systems Analysis Programme <www.etsap.org/tools.htm>.

${ }^{5}$ Bhatt, V.; Friley, P.; Lee, J. Integrated Energy and Environment Systems Analysis Methodology for Achieving Low Carbon Cities, Journal of Renewable and Sustainable Energy, of the American Institute of Physics, Vol. 2, 031012 (2010).
} 


\subsection{Technology Choice in MARKAL}

Reference case estimates of end-use energy service demands (e.g., residential and commercial buildings, car road travel; residential lighting; steam heat requirements in the paper industry; etc.) are provided by the user. In addition, the user provides estimates of the existing stock of energy related equipment in all sectors, and the characteristics of available future technologies, as well as present and future sources of primary energy supply and their potentials.

Using these as inputs, MARKAL aims to supply energy services at minimum global cost (more accurately at minimum loss of surplus) by simultaneously making equipment investment and operating, primary energy supply, and energy trade decisions, by region. For example, if there is an increase in residential lighting energy service relative to the reference scenario (perhaps due to a decline in the cost of residential lighting, or due to a different assumption on GDP growth), either existing generation equipment must be used more intensively or newpossibly more efficient - equipment must be installed. ${ }^{6}$

The choice by the model of the generation equipment (type and fuel) is based on the analysis of the characteristics of alternative generation technologies, on the economics of the energy supply, and on environmental criteria. MARKAL is thus a vertically integrated model of the entire extended energy system. The scope of the model extends beyond purely energy oriented issues, to the representation of environmental emissions or climate change interactions/impacts, and materials (like water), related to the energy system. In addition, the model is admirably suited to the analysis of energy and environmental policies, which may be represented with accuracy due to the explicitness of the representation of technologies and fuels in all sectors. In MARKAL, the quantities and prices of the various commodities are in equilibrium, i.e. their prices and quantities in each time period are such that the suppliers produce exactly the quantities demanded by the consumers. This equilibrium has the property that the total surplus is maximized. (Ibid Loulou et al, 2005)

Technology choice in the MARKAL framework is based on the present value of the marginal costs of competing technologies in the same market sector. On the demand side, the marginal cost of demand devices is a function of levelized capital cost, operations and maintenance (O\&M) cost, efficiency, and the imputed price of the fuel used by these devices. For a specific energy-service demand and period, the sum of the energy-service output of competing technologies has to meet the projected demand in that period. The relative size of the energy-service output (market share) of these technologies depends not only on their individual characteristics (technical, economic, and environmental), but also on the availability

\footnotetext{
${ }^{6}$ Loulou, R., U. Remne, A. Kanudia, A. Lehtila, G. Goldstein (2005). Documentation for the TIMES Model. Available from Energy Technology Systems Analysis Programme <www.etsap.org/tools.htm>
} 
and cost of the fuels (from the supply side) they use. The actual market size of a demand sector in the future depends on the growth rate of the demand services and the stock turnover rate of vintage capacities. MARKAL dynamically tracks these changes and defines future market potential. Another factor considered in MARKAL that affects the market penetration of a specific demand device, is the sustainability of the expansion in the implied manufacturing capacity to produce these devices (Ibid Bhatt et al, 2010).

On the supply side, the technology choices made in MARKAL are based on the imputed price of the energy products (e.g., coal, natural gas, biomass) and the marginal cost of producing energy from conversion technologies (e.g., power plants, burners, distributed generation plants) to meet electricity demand (endogenously determined in MARKAL). The cost of resource input for production (exogenously projected in MARKAL) such as imported oil prices and cost of natural gas, together with the characteristics of supply technologies (including electricity generation) determine the market share of a particular fuel type and the technology that uses it. The supply-demand balance achieved for all fuels under the least energy-system cost represents a partial equilibrium in the energy market. In particular, the intertemporal new investments in energy production and consumption technologies under this equilibrium determine the market deployment of these technologies. Additionally, policies can be modeled that explicitly or implicitly provide economic incentives for less competitive technologies to accelerate their learning curves or market penetration (Ibid Bhatt et al, 2010).

\subsection{Customizing MARKAL for New York City Case Study}

The existing NYC-MARKAL was built by BNL with the help of a Pollution Prevention Grant from the Environmental Protection Agency (EPA) to evaluate mitigation measures for peak-load reduction and easing of the "urban heat island" effect in a Lower Manhattan case-study, and to assess impacts of these policies in reducing electricity peak, annual demand and emissions over the long-term (2000-2025) (Linky et al., 2008). The current project expanded the NYC-MARKAL model and used it to examine alternative strategies of implementing green technologies in selected case studies of CUNY's campus buildings, housing projects, hospitals, and hotels that are recognized by the EPA Energy Star Buildings Program and EPA Portfolio Manager.

New York City-specific historical energy demand-supply data were used to establish the base year (2010) in the model. The base year provides a calibrated state (partial equilibrium) of the entire energy system in a static year, based on which future energy-environmentaleconomic scenarios can be formulated. PlaNYC 2030 was used to project various factors including the population, energy demands and production. Characteristics of specific energy technologies (existing or future) were taken from the US MARKAL database, calibrated each year to the Annual Energy Outlook (AEO) of the USDOE's Energy Information Administration (EIA) and other sources as outlined below: 
- New York City Energy Policy Task Force, PlaNYC 2030, NYC Emissions Inventory, NYC Long-term Planning and Sustainability Office, Regional Plan Association, New York Building Council, New York-New Jersey Port Authority, Metropolitan Transportation Authority, New York Power Authority and other organizations.

- New York State Energy Research Authority (www.nyserda.org) has carried out various State- and City-based surveys and topical reports, including Hydrogen Roadmap and distributed generation potential study.

- Energy Information Administration (www.eia.gov) provides substantial information including, the electricity generators information and the Residential and Commercial Building Energy Consumption Survey (RECS and CBECS).

- US Environmental Protection Agency: energy and air emission databases, portfolio manager, EGRID database of power plant energy and emission information.

The overall approach to developing the Baseline Case was to update the existing model used for the UHI project, using the latest energy and economic information available. The development of the expanded New York City model for the study involved a comprehensive update of the data inputs and enhancement of the energy system configuration built in an earlier version. To establish the Baseline Case, all parametric values and assumptions (technical, environmental, and economic) required in the model were updated based on the latest available data and trends for New York's energy markets during the period under consideration (2010 - 2030). The model solution attains an inter-temporal partial equilibrium that provides optimal energy demand-supply balances and development path, associated environmental emissions and economic costs.

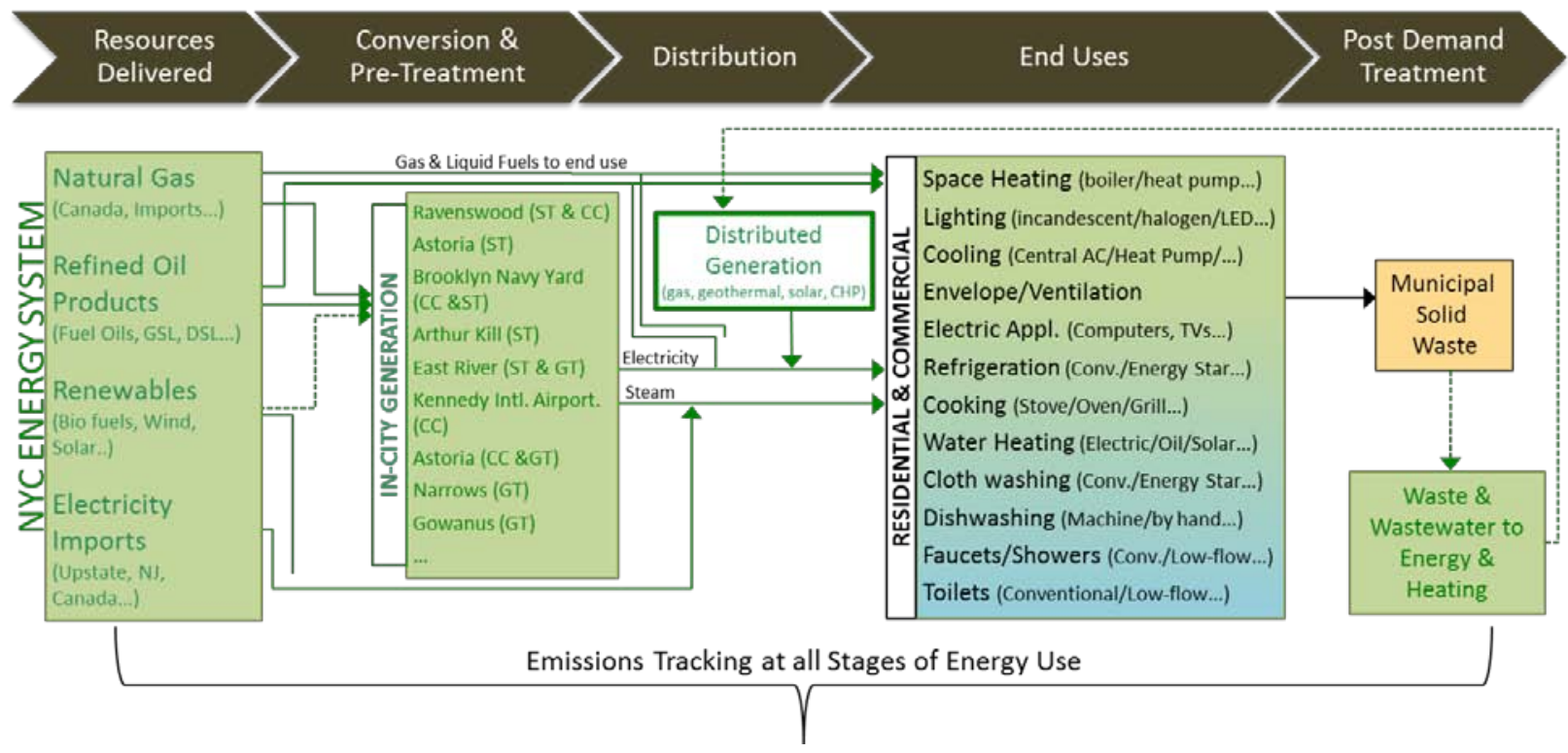

Figure 2: Reference Energy System for New York City MARKAL Model 
The Reference Energy System (RES) underlying the model as depicted in Figure 2, requires input data (actual and projected) from primary energy supply (e.g. gasoline or natural gas imports), intermediate conversion and related processes (e.g. electricity generation), to enduse technologies (e.g. air conditioners) that satisfy energy service demands (e.g. space conditioning). Each element in RES is characterized by three groups of data: technical (e.g. efficiency), economic (e.g. capital and resources cost), and environmental (e.g. carbon and other emission coefficients). The other two categories are economic parameters of energy carrier/technology and emission factors associated with elements within the four building blocks.

Figure 2 depicts schematics of the interrelated tasks in the development of the Baseline Case. In general, New York-specific historical energy demand-supply data were used to establish the base year (2010) RES. The base year RES provides a calibrated state (partial equilibrium) of the entire energy system in a static year, based on which future energyenvironmental-economic scenarios can be formulated. If no New York-specific data were available (characteristics of a specific technology, existing or future); they were taken from US MARKAL database, calibrated each year to the Annual Energy Outlook (AEO) of the USDOE's Energy Information Administration (EIA). It should be noted that there are uncertainties inherent in the input data and projections used to develop the Baseline Case (also referred as 'Business as Usual case (BAU)). In considering the results of modeling analysis, it is most useful to focus on the differences between the scenarios representing the conditions with and without the additional technologies, policies and measures selected for the study than on the absolute numerical results for any scenario. This approach minimizes the significance of these uncertainties on the impact of alternative scenarios measured against the Baseline Case developed here. 


\section{Campus-Neighborhood Partnerships}

A general theme of this project is "think globally, act locally." In an attempt to become more deeply involved in the communities surrounding CUNY campuses, this project focuses on University campuses as locally engaged partners in the communities in which it is situated (Bromley, 2006). Universities are often criticized for being too global and inadequate in terms of the local component involved in serving the surrounding communities (Baker-Minkel, et al, 2004). This project acknowledges and further promotes existing efforts within CUNY to connect with the local communities surrounding each campus. By actively engaging CUNY administration, faculty and students with local communities, CUNY campuses function as stakeholders within their communities. The success of these community-based efforts is premised on a commitment by CUNY to assign resources, carry out research, and form strategic alliances for the reciprocal benefit of local stakeholders. This promotion of reciprocity is timeconsuming and is difficult both to initiate and sustain. Despite these limitations, we see it as essential in developing sustainable and meaningful dialogues between CUNY campuses and local community members. Research suggests that the diffusion of environmental initiatives is simultaneously influenced by processes operating within "nested organizational fields" at local, national and global levels (Vasi, 2007).

This project fits into Velazquez, et al.'s proposed sustainable university model in that it contains components of education, research, outreach and partnership, and sustainability on campus (2006). This model was developed through empirical investigation of university sustainability initiatives and indicates the importance of the development of a sustainability committee to organize campus-wide initiatives, obtain funds, disseminate information and ensure that policies are adhered to. This important component to university sustainability initiatives has already been initiated at CUNY and is currently underway throughout each campus (see Sustainable CUNY).

Some CUNY campuses have joined Campus Compact in an attempt to promote community service, civic engagement, and service learning. Campus Compact is a national coalition of more than 1,100 college and university presidents - representing some 6 million students - dedicated to promoting community service, civic engagement, and service-learning in higher education (Campus Compact, 2007). Their mission is clear and fits with the overarching agenda of this project: "to advance the public purposes of colleges and universities by deepening their ability to improve community life and to educate students for civic and social responsibility." The vision guiding the mission of Campus Compact is one that this project hopes to utilize: it "envisions colleges and universities as vital agents and architects of a diverse democracy, committed to educating students for responsible citizenship in ways that both deepen their education and improve the quality of community life." Campus Compact challenges all of higher education to make civic and community engagement an institutional priority. Of the 76 current Campus Compact members in New York State, current CUNY 
member campuses include City College, Lehman College, Queens College, and Queensborough Community College. An aim of this project will be to connect additional CUNY campuses with Campus Compact as a prototype to encourage membership and promote the mission and vision behind it.

\subsection{Case Study I: CCNY and Manhattan Community Board 9}

The development of an effective university-community partnership requires that we identify a set of common interests that could form the foundation for cooperative effort. Following hearings held by the City Planning Commission, a revised "Community Board 9 Manhattan 197-a Plan" was adopted in 2007. The City Planning Commission endorsed a number of the community sustainability goals incorporated in the draft plan, including: 1 , waste reduction; 2 , improved air quality; 3 , green building standards, including strategies for green design; and 4, increased planting and green roofs where possible. The convergence of campus and community environmental goals creates an opening for the university to create green technology demonstration projects on the campus, and to make the results of these projects accessible to community partners.

\subsection{Shared Goals: CCNY and Community Planning Board 9}

The research team believes that providing strategies to improve livability offers the highest value to the residents of community board 9. Extensive research throughout the five boroughs suggests that increasing permeable and/or vegetated surfaces can significantly change urban micro climates. Livability correlates inversely to Heat Vulnerability Index. Livability can be evaluated as heat stress, cooling degree days or air quality non-attainment days. All of these indicators can be tied to the Urban Heat Island (UHI) effect. UHI is the result of high density of urban masonry and asphalt surfaces that function as thermal masses absorbing shortwave radiation and reradiating long wave radiation or heat. Livability declines in many highly developed areas as ambient temperatures increase. Decreasing urban livability can be correlated to increasing electric grid stress.

Early summer mornings in urban neighborhoods are pleasant and the grid is unstressed. As the day progresses, temperatures increase correlating with grid and respiratory stress. Late afternoon combined business and residential air conditioning use peaks along with transportation stress leading to air quality alerts and threats of grid overload. Solar PV has been proposed as one of the solutions to help alleviate peak demand problems attributable to AC loads. (Perez et al, 2005) Electric load forecasting estimates AC loads account for over $65 \%$ of system annual peak demand. (Kandil et al, 2000)

In their "197-a Plan", adopted in 2007, CB9 identified permitting of green roofs and other vegetative building surfaces as a priority. Amory Lovins has documented the improvement of community life resulting from introduction of vegetative surfaces. (Lovins et 
al,1999) Recent work at CUNY (Lynn et al, 2008) suggests that high urban summer time ambient temperatures or UHI can be mitigated by planting trees at street level and increasing the reflectivity of roofs. CUNY GIS-based modeling suggests that in addition to modulating ambient temperatures, vegetative surfaces can maintain localized air quality through photosynthesis. (Solecki, 2005) Extensive physical testing of green roofs in the US, Canada and elsewhere has built a conclusive body of knowledge. Karen Liu in Ottowa, Ontario and Stu Gaffin at Columbia concur that green roofs can reduce heat flux across building roof membranes by as much as $80 \%$. (Gaffin 2010), (Liu, 2003)
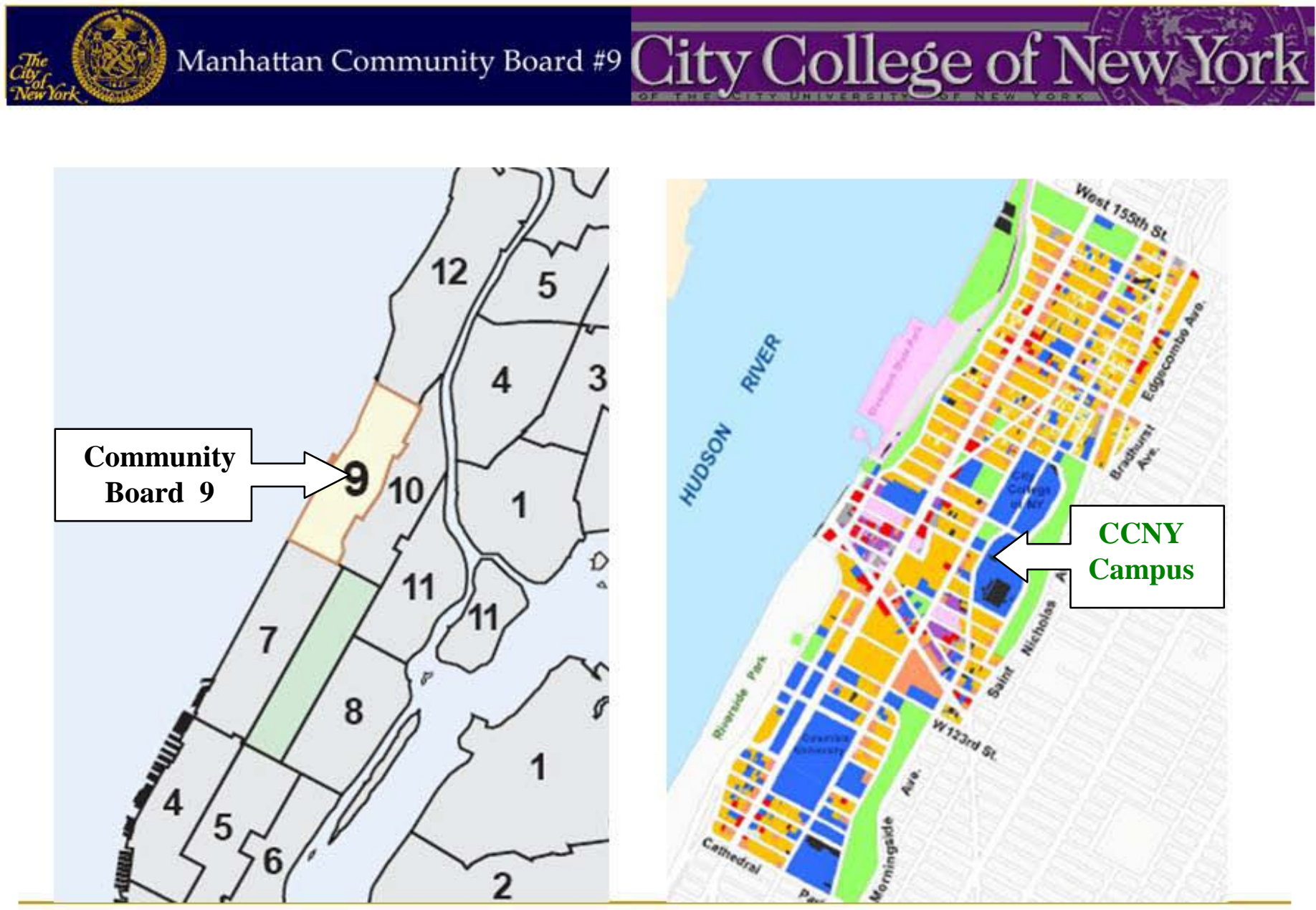

Figure 3: Maps Indicating CB9 and CCNY

\subsection{MARKAL Analysis for Buildings Energy Conservation \& Efficiency-CB9}

In considering the results of modeling analysis, it is most useful to focus on the differences between the scenarios representing the conditions with (Baseline Case + ) and without (Baseline 
Case) the additional technologies, policies and measures selected for the study than on the absolute numerical results for any scenario. This approach minimizes the significance of these uncertainties on the impact of alternative scenarios measured against the Baseline Case developed here. Figures 4 shows buildings energy demands for various uses for the Community Board 9 (CB9), as modeled in MARKAL.

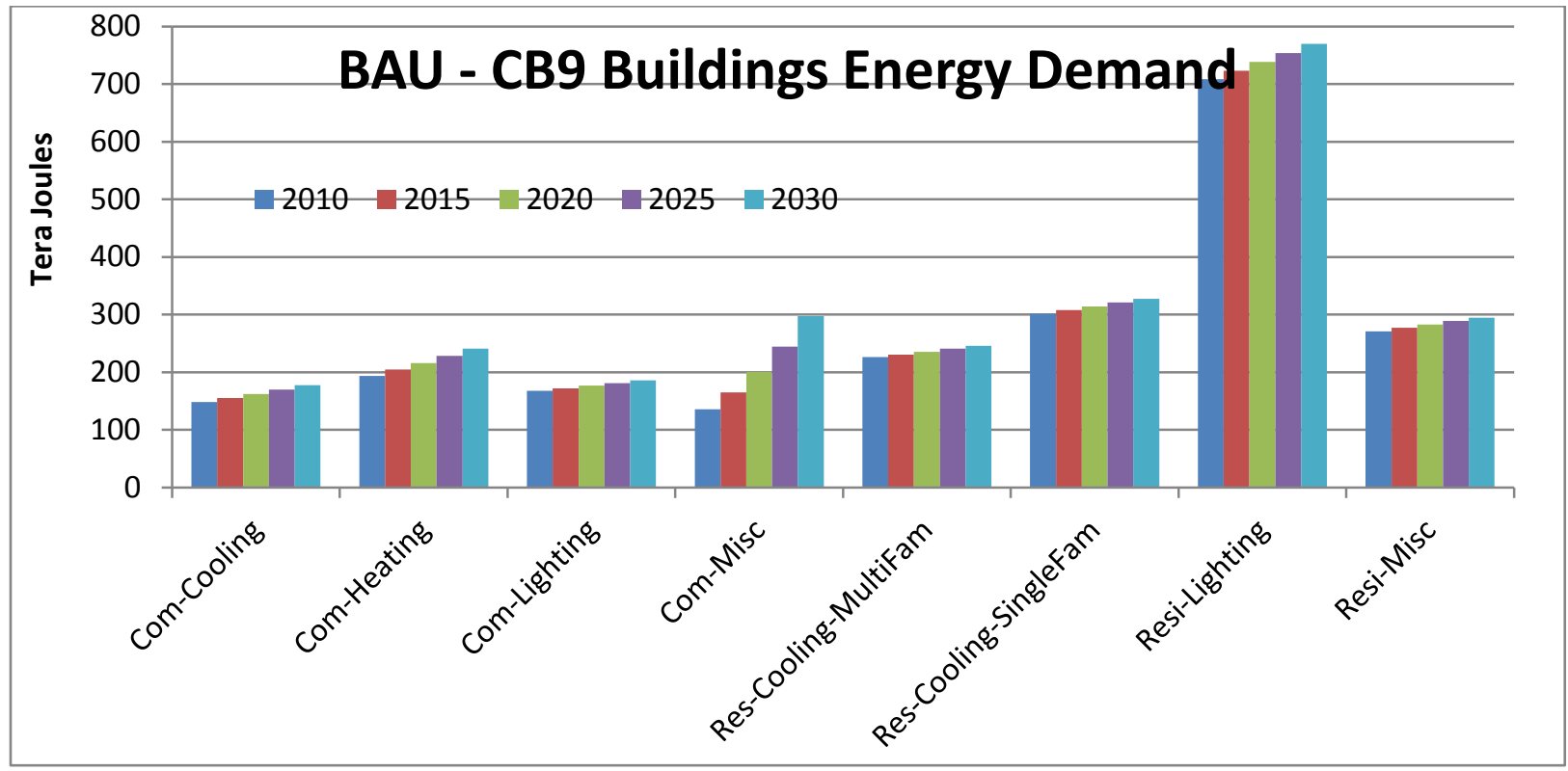

Figure 4: CB9 - Buildings Energy Demands in the Business as Usual (Base Line) Case in MARKAL

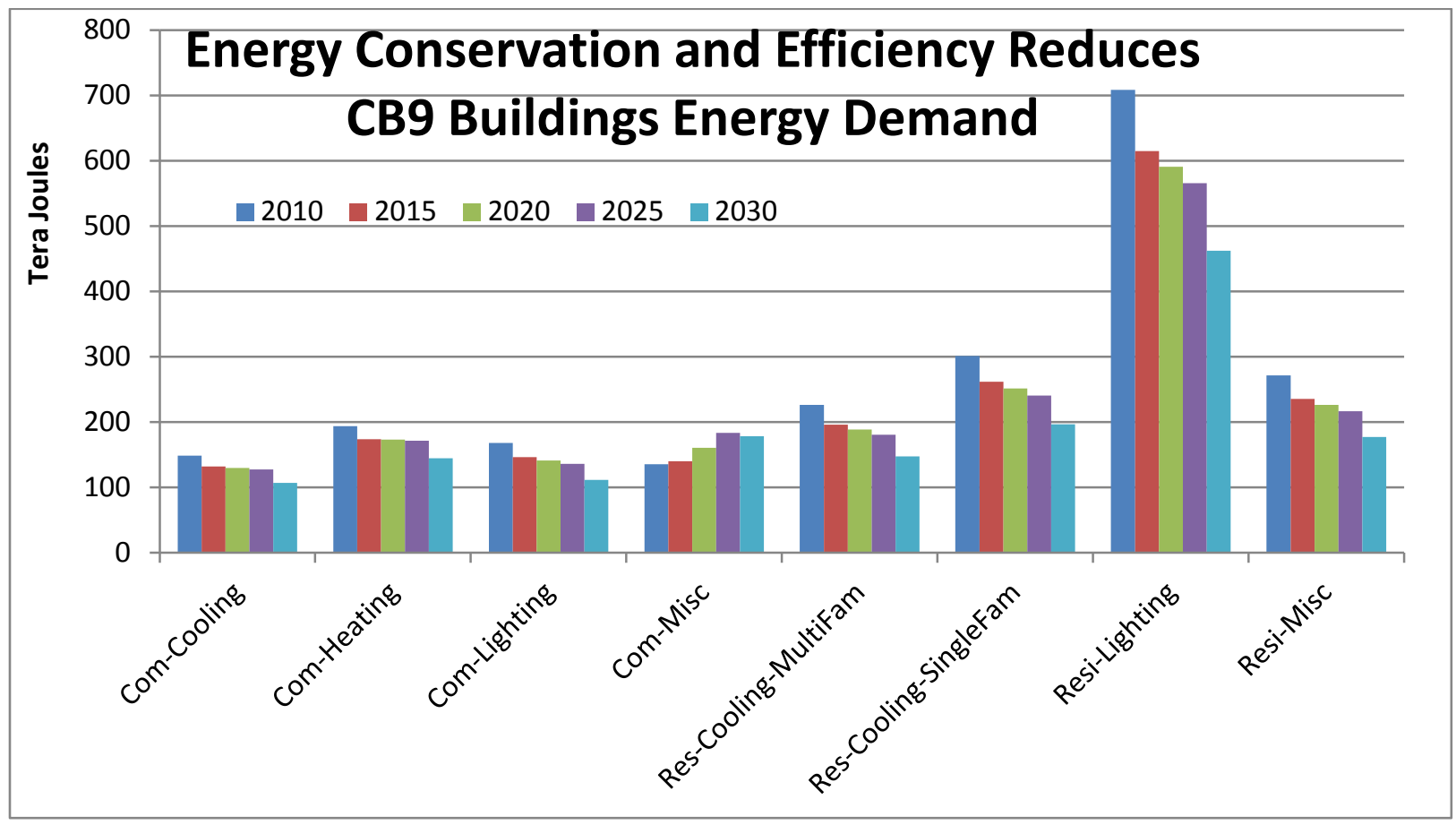

Figure 5: CB9 - Buildings Energy Demands with Energy Conservation and Efficient Technologies 
The demand module of the model simulates the "business as usual" electricity demand by end-use in these building space types. Altered demand patterns attributable to efficiency programs (e.g., Energy Star), load management, conservation, and building codes are generated to compare with "business as usual", as highlighted in Figures 5. Such energy conservation and efficiency measures reduce demands to the tune of $20 \%$ by $2020,25 \%$ by 2025 and $40 \%$ by 2030 , which in turn reduce the need for electricity generating capacity in the long-term. Since the marginal cost of implementing phased-in energy conservation and efficiency measures are substantially low compared to investing in capital intensive new generation capacity, MARKAL model's least-cost approach avoids new power plants. This is accomplished by measuring their difference in electricity use and power load at the sub-station level which is a part of the MARKAL model solution. Figure 6 showcases electricity capacity needed by CB9 case study in two scenarios 1) Business as Usual/Base Case (BAU), and 2) Energy Conservation and Efficiency (EE).

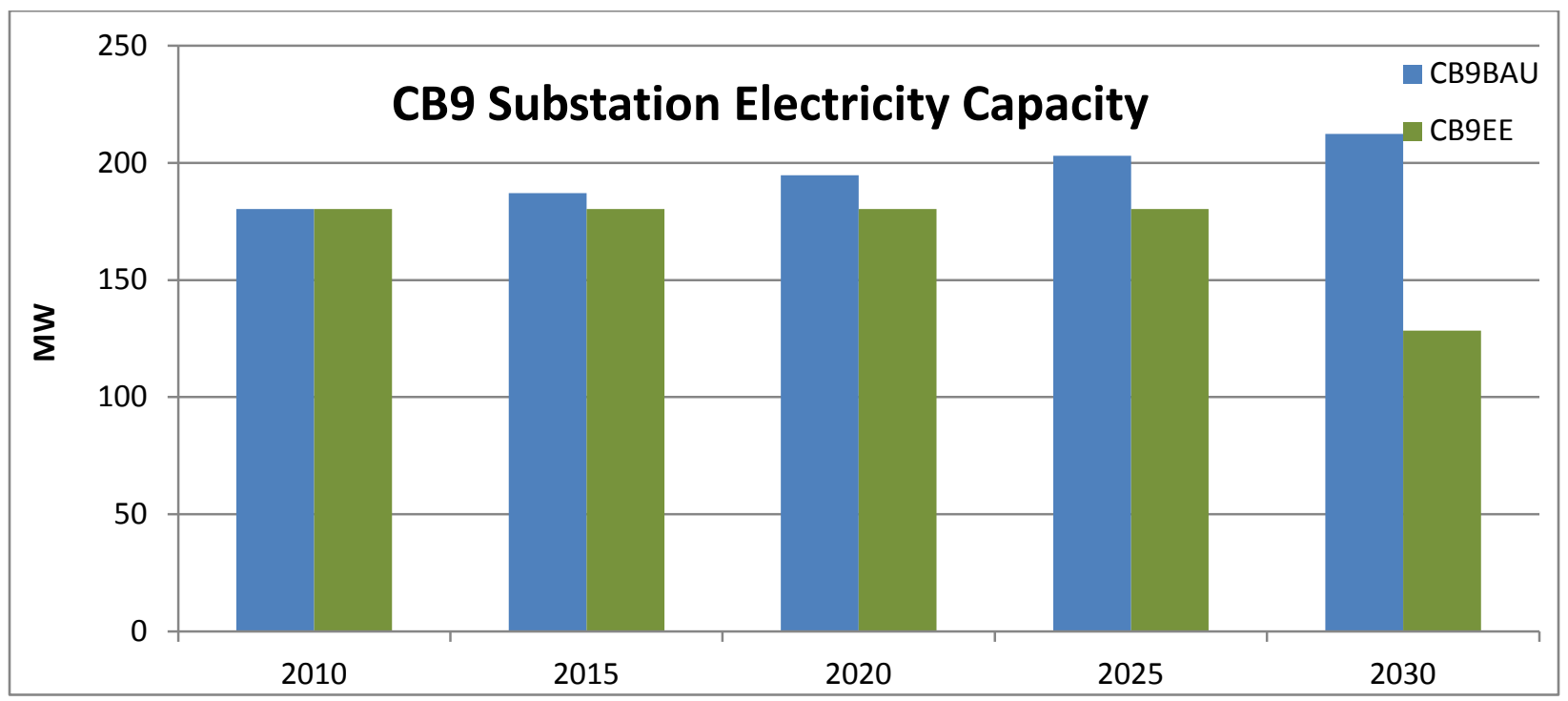

Figure 6: CB9 - Comparison of Electricity Capacity Needed in Two Scenarios

Preliminary results obtained from this portfolio approach indicate that Energy Star and UHI mitigation strategies, employed in tandem, can potentially lower aggregate demands, including air conditioning, to the tune of $25-40 \%$ for buildings. Figure 7 highlights electricity needed and saved over years. 


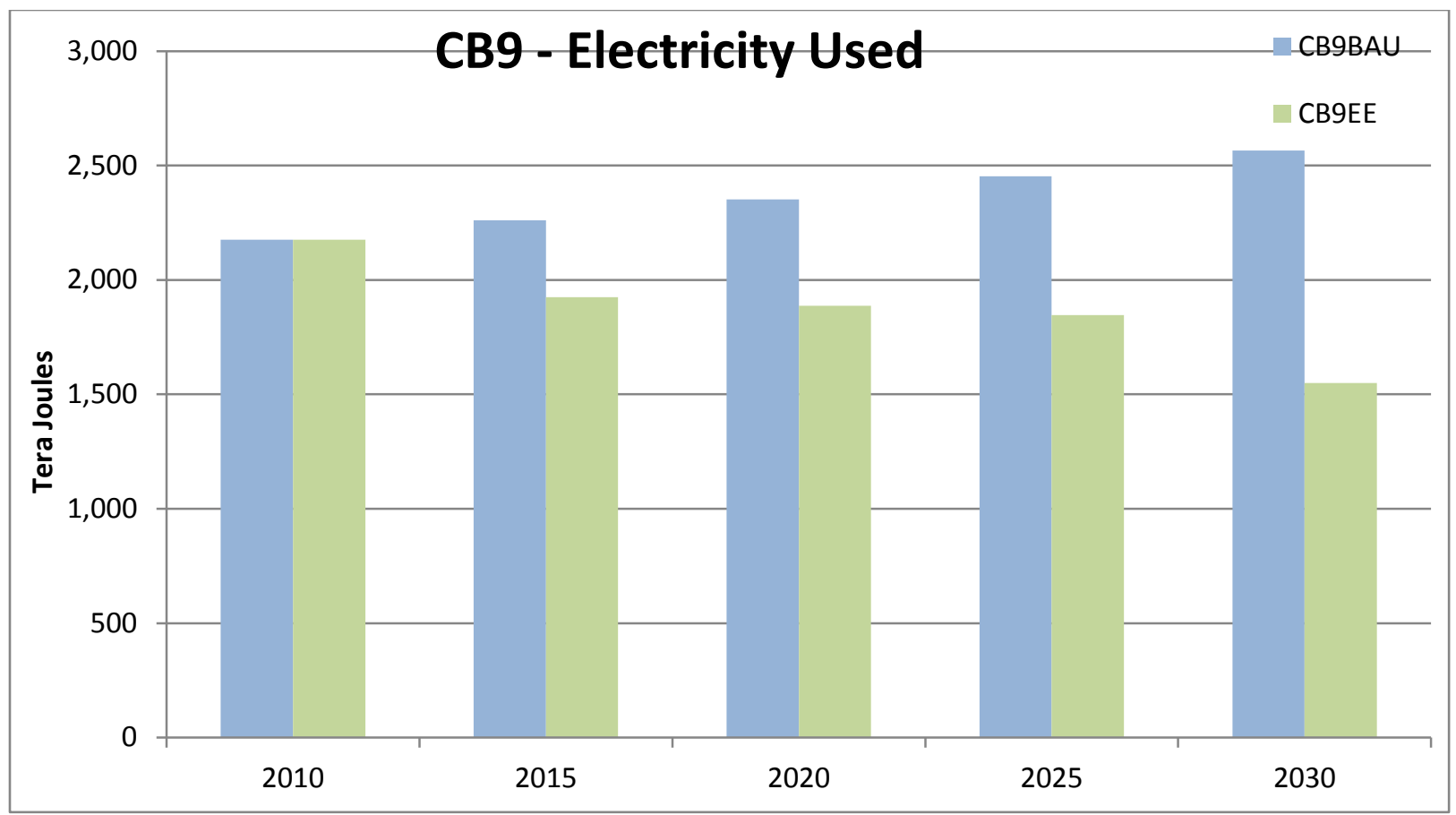

Figure 7: Significant Electricity Saved over time in EE Scenario for CB9 Case study

The differences in the sub-station data (e.g. electricity, emissions) feed into the entire power network supply New York City to generate the impact of programs and measures on fuel use, greenhouse gas (GHG) and criteria pollutant emissions at specific power plants, as well as energy system costs and future expansion plans for electricity generation for the long-term (2010-2030), as outlined in figure 8.

New York City is a huge load pocket (areas where the majority of capacity to serve the load must be locally installed due to existing transmission limitations). These areas have additional location reliability requirements. The Federal Electricity Regulatory Commission mandates that to meet peak demand with adequate reserves, 80 percent of the peak demand capacity must be located physically "in-city". Due to a very high density, expensive real-estate and planning regulations, siting new energy facilities in New York City has become nearly impossible. It is obvious from this case study that energy conservation and efficiency can save future expansion of new installed capacity in the City as highlighted in figure 8. Citywide $\mathrm{CO} 2$ emissions saved by eliminating the need for installing new capacity in the EE case compared to BAU are quantified in figure 9. 


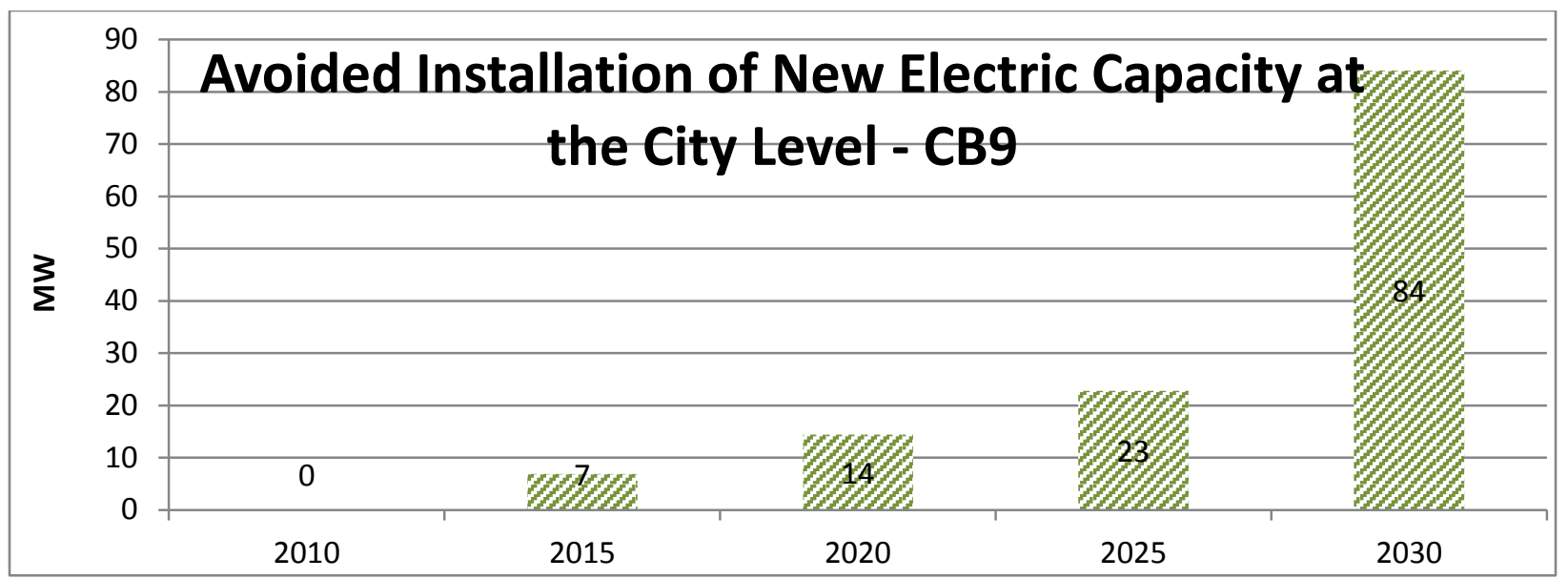

Figure 8: CB9 - Cumulative Avoided Installation of New Electric Capacity at the City Level Compared to BAU Scenario

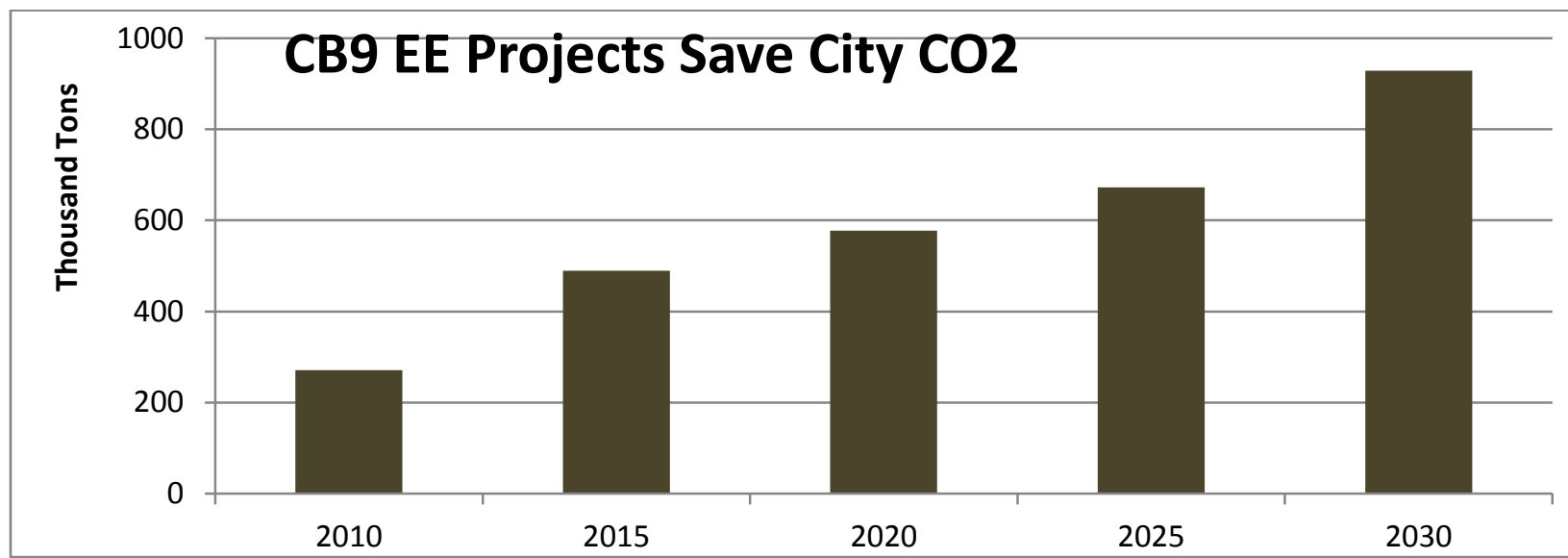

Figure 9: CB9 - Cumulative CO2 Emissions Avoided Compared to BAU Scenario

\subsection{The Environmental Impacts of Green Technologies at CCNY}

The CCNY Greenhouse Gas Inventory Program (Sinha and Spiegel, 2008) provides a detailed assessment of energy use and emissions of carbon and criteria pollutants at CCNY in support of the commitments to reduce carbon emissions undertaken by CUNY in response to New York City's PlaNYC 2030. The inventory accounts for emissions of greenhouse gases (carbon dioxide, methane and nitrogen dioxide). It provides a baseline against which to measure the impacts of policies and technologies that affect the three major sources of GHG emissions: indirect emissions associated with purchased electricity, stationary source emissions resulting from the combustion of natural gas or fuel oil in campus boilers, and commuting emissions. In its effort to achieve the PlaNYC 2030 carbon emissions goals, CCNY has 
undertaken projects ranging from fuel switching (from \#6 fuel oil to natural gas), energy conservation, recycling, and reducing the availability of on-campus parking. These efforts have environmental and urban public health implications that transcend the issue of the carbon footprint of the CCNY campus.

\section{CCNY MARKAL Case Study}

The NYC MARKAL model was expanded to incorporate CCNY-specific energy use and technologies. The model evaluated long-term (through 2035) energy and environment benefits and economic impacts of deploying energy efficient LED lighting retrofits and rooftop photovoltaic array installation. Data were assimilated from various documents provided by CCNY (Letkiewicz, 2010; Sinha \& Spiegel, 2008). The University can implement various energy efficiency and renewable energy measures. But for the simplicity, a base case scenario representing the business-as-usual was generated to compare three additional scenarios: i) Alternative 1 evaluates full LED lighting replacements for fixtures by limiting investment in lessefficient T8 lighting and incorporating the phase-out of T12 lighting made effective July 1, 2010 by the National Lighting Bureau (NLB Press Release), ii) Alternative 2 evaluates the impacts of rooftop photovoltaic array electricity generation on the CCNY campus, and iii) Alternative 3 studies the cumulative impacts of Alternatives 1 and 2. Technology phase-in increases savings over time for the University.

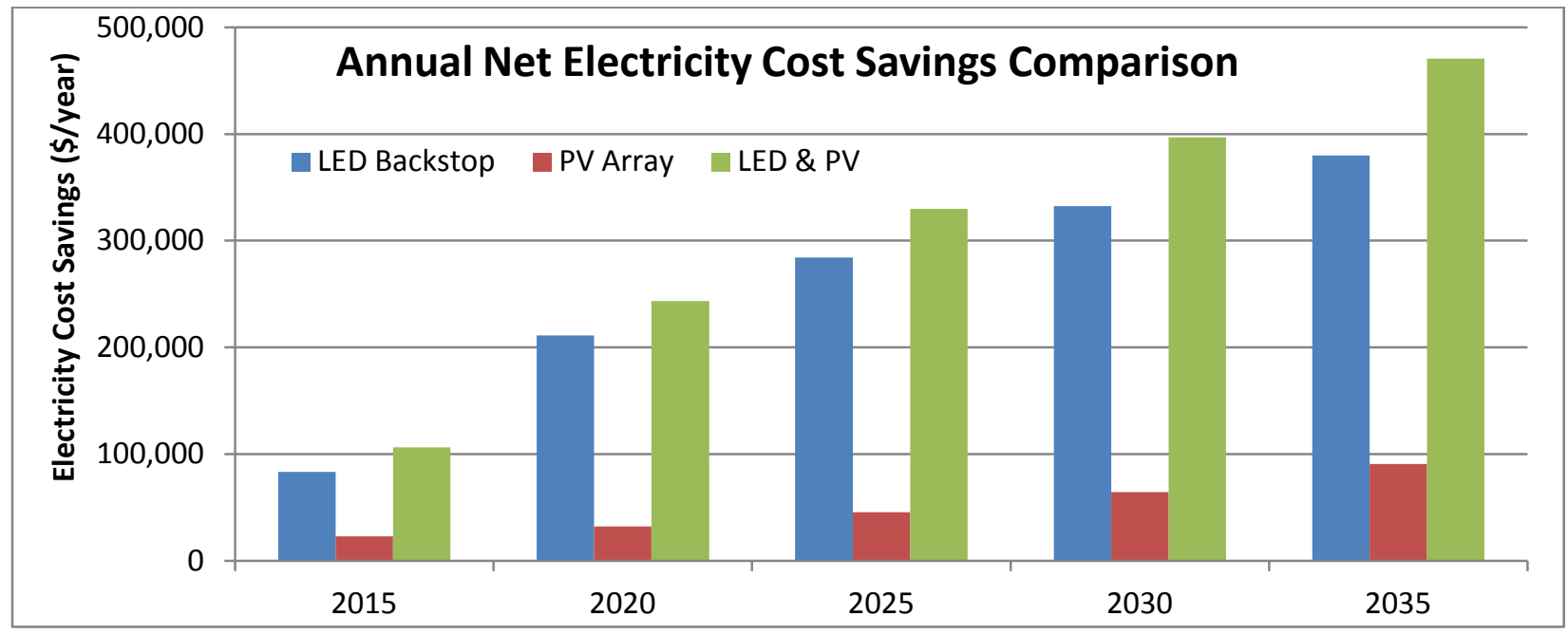

Figure 10: CCNY Annual Net Electricity Cost Savings Comparison (\$/year)

We found that all the alternatives reduced annual net electricity use, electricity costs, and carbon emissions, with the amount of reductions increasing over time. Alternative 1 (LED lighting retrofits) resulted in greater reductions than Alternative 2 (installation of rooftop photovoltaic arrays), likely due to the lower capital costs and high efficiency of the lighting. Our results, with a comparison of the impacts of each alternative with respect to the base case, can be found in Figures 10-12. 


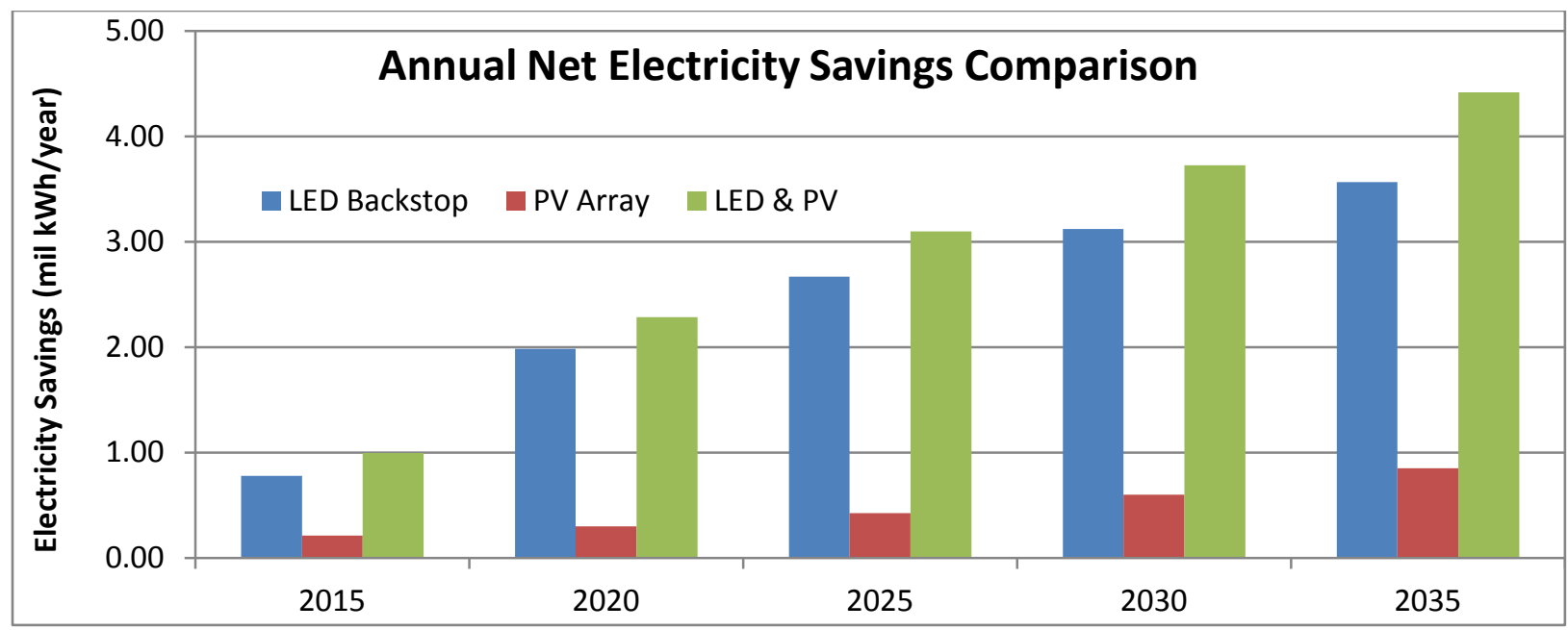

Figure 11: CCNY Annual Net Electricity Savings Comparison (million kWh/year)

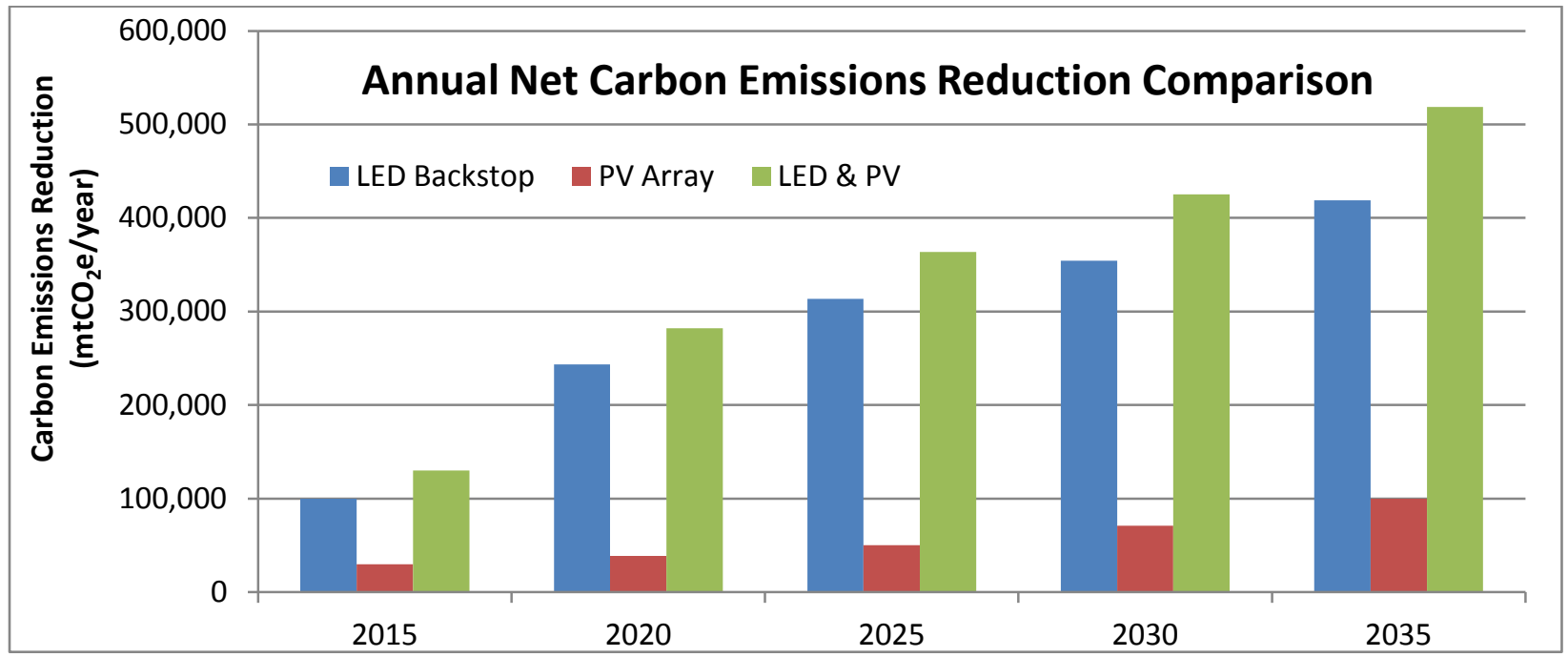

Figure 12: Annual Net Carbon Emissions Reduction Comparison ( $\mathrm{mtCO}_{2} \mathrm{e} / \mathrm{year}$ )

\subsection{Estimating Green Roof Associated Reduction of Electric Load}

Using a simplified approach to estimate green roof impact on air conditioning load at CCNY, we assumed that roof top heat flux during summertime air conditioning months translated to air conditioning load. Using Jeff Sonne's air conditioning load estimate, we assumed that every watt of heat energy removed by air conditioning uses 3 watts of electricity from the grid (Sonne, 2006). This first cut at estimating the impact of green roofs on CCNY summer electric load suggests that installation of green roofs on $50 \%$ of CCNY roofs could significantly reduce incremental summer time load associated with $\mathrm{AC}^{7}$

\footnotetext{
${ }^{7}$ One year of energy use data is not adequate to precisely quantify incremental energy use. However, this calculation is intended to provide a rough "order of magnitude" comparison.
} 
Table 1: Potential of Avoided AC Load by Deploying Green Roofs at CCNY

\section{7-2008 CCNY Energy Use (kWh/mo)}

$\begin{array}{lr}\text { avg non summer energy use } & 4,353,575 \\ \text { avg summer energy use } & 4,893,993 \\ \text { incremental summer energy use (AC load) } & 540,418 \\ \text { \% difference } & 11 \%\end{array}$

(the summer AC period for NY downstate utilities runs from May 1 thru Oct 1 )

$50 \%$ reduction in average incremental summer load could eliminate the need for infrastructure upgrades in impactectretworks

\begin{tabular}{|c|c|c|c|c|c|c|}
\hline & $\begin{array}{c}\text { 100\% Green } \\
\text { Roof }\end{array}$ & \% summer use & $\begin{array}{c}75 \% \text { Greel } \\
\text { Roof }\end{array}$ & \% symmer use & $\begin{array}{c}50 \% \text { Green } \\
\text { Roof }\end{array}$ & $\begin{array}{c}\text { \% summer } \\
\text { use }\end{array}$ \\
\hline May & 291,663 & $6 \%$ & 218,747 & & 145,832 & $3 \%$ \\
\hline June & 508,058 & $10 \%$ & 381,044 & $8 \%$ & 254,029 & $5 \%$ \\
\hline July & 602,770 & $12 \%$ & 452,078 & $9 \%$ & 301,385 & $6 \%$ \\
\hline August & 583,326 & $12 \%$ & 437,495 & $9 \%$ & 291,663 & $6 \%$ \\
\hline Sept & 479,833 & $10 \%$ & 359,875 & $7 \%$ & 239,916 & $5 \%$ \\
\hline
\end{tabular}

(heat flux estimates from Liu \& Baskaran, Ottowa, 2003)

\section{CUNY, the Community \& the Grid}

In addition to offering potential solutions to high indoor temperatures in the summer, green roofs, vegetative and pervious surfaces can also reduce ambient temperatures. Direct field observations show urban green spaces can lower daytime summer temperatures at street level by as much as 1.9 deg C. (Hamada, 2010) Reducing ambient outdoor and indoor temperatures can generate a cooling feedback loop. Not only does air conditioning contribute to energy demand at a time when the grid delivers energy most inefficiently but it also dumps indoor heat outdoors and generates waste heat from mechanical equipment. Urban cooling may create a feedback loop to reduce temperatures in all spaces as well as reducing Peak Day grid stressors.

\section{Cooling the Community}

Using the same process used to estimate green roof impact on the CCNY campus, green roof associated air conditioning load reductions were estimated for Community Board 9.

Green Roof air conditioning load reduction was then compared to estimates of air conditioning load generated by the NYC Office of Long Term Planning and Sustainability (OLTPS) (Howard et al 2012). 


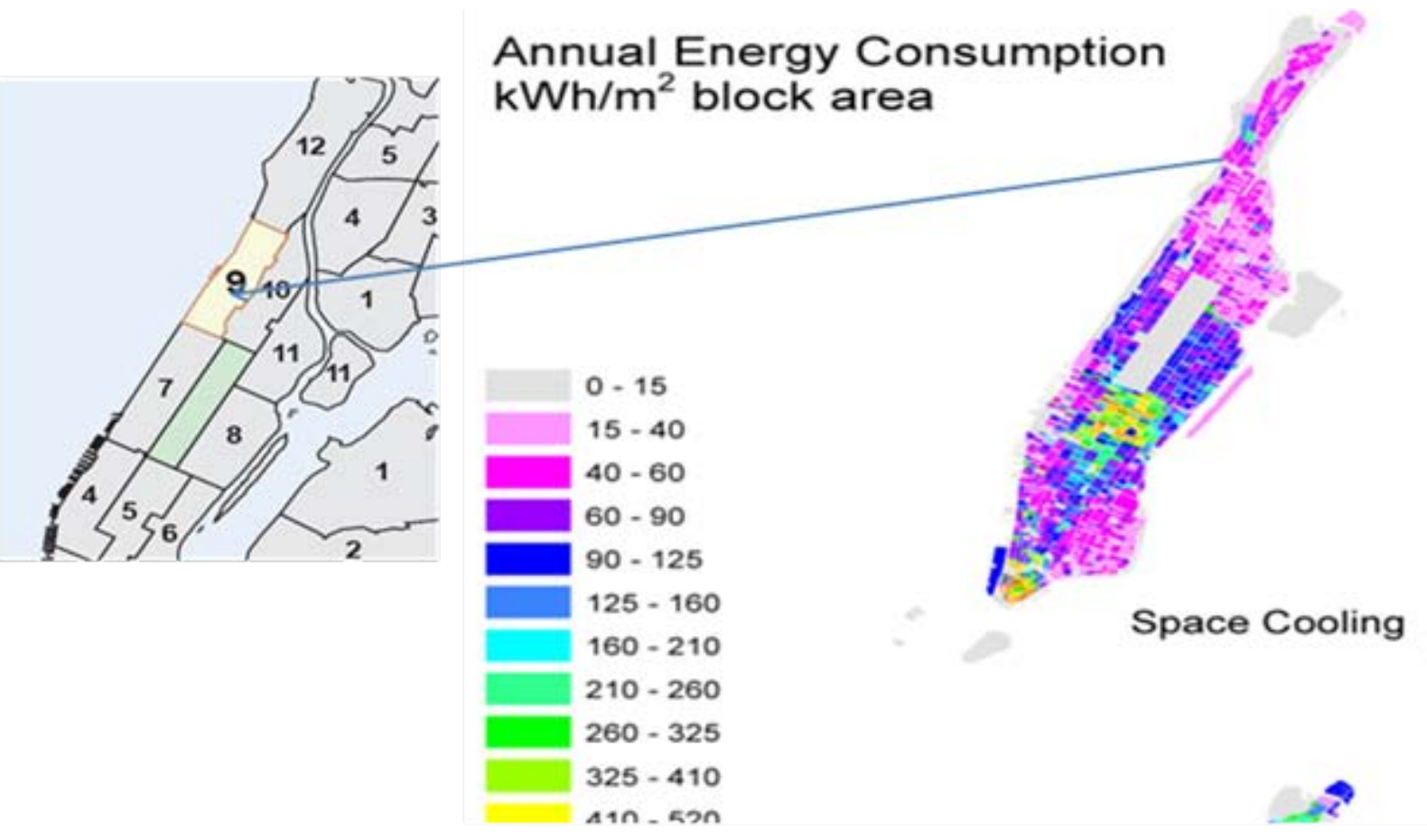

Figure 13: CB9 - Electricity Consumption by Block

Howard et al estimate that CD9 homes and businesses use 40-60 kWh per square meter of block area on space cooling annually. The space cooling map above was generated from energy use modeling based on NYC OLTPS data on non-public buildings of 50,000 sf or greater. The model assumes end use is primarily dependent on building function, whether residential, educational or office and not on construction type or the age of the building (B. Howard et al. / Energy and Buildings 45 (2012) 141-151). These estimates for annual cooling energy use were compared with potential green roof associated AC load reductions in CB9.

Table 2: CB9 - Annual AC Electricity Consumption Estimates

\begin{tabular}{rccc} 
& \multicolumn{4}{c}{ CB9 annual AC Load $(\mathrm{kWh})$ for 19.6x10 } & sf of block area \\
Energy Intensity & $40 \mathrm{kWh} / \mathrm{m}^{2}$ & $50 \mathrm{kWh} / \mathrm{m}^{2}$ & $60 \mathrm{kWh} / \mathrm{m}^{2}$ \\
Annual AC Load (kWh) & $87,324,444$ & $109,155,556$ & $130,986,667$ \\
\hline $100 \%$ green roof AC reduction ( $\mathrm{kWh})$ & $75,878,611$ & $75,878,611$ & $75,878,611$ \\
\% AC load & $87 \%$ & $70 \%$ & $58 \%$ \\
\hline $75 \%$ green roof AC reduction ( $\mathrm{kWh})$ & $56,908,958$ & $56,908,958$ & $56,908,958$ \\
\% AC load & $65 \%$ & $52 \%$ & $43 \%$ \\
\hline $50 \%$ green roof AC reduction ( $\mathrm{kWh})$ & $37,939,306$ & $37,939,306$ & $37,939,306$ \\
\% AC load & $43 \%$ & $35 \%$ & $29 \%$
\end{tabular}


Annual Cooling Load estimates for CB 9 are 40 to $60 \mathrm{kWh}$ per square meter of block area. The results of these preliminary estimates are interesting, however the assumption that green roof reductions in heat flux across roof membranes translate directly to reductions in air conditioning load requires further verification and refinement. Based on the quality of historical construction it seems likely that this is truer for older buildings than for newer ones. If heat flux correlates closely to indoor temperatures in older buildings, green roofs may offer the greatest benefit to old multifamily and tenement buildings in low income neighborhoods. Figures 14 and 15 highlight energy and emissions savings in MARKAL analysis for deploying Green Roofs.

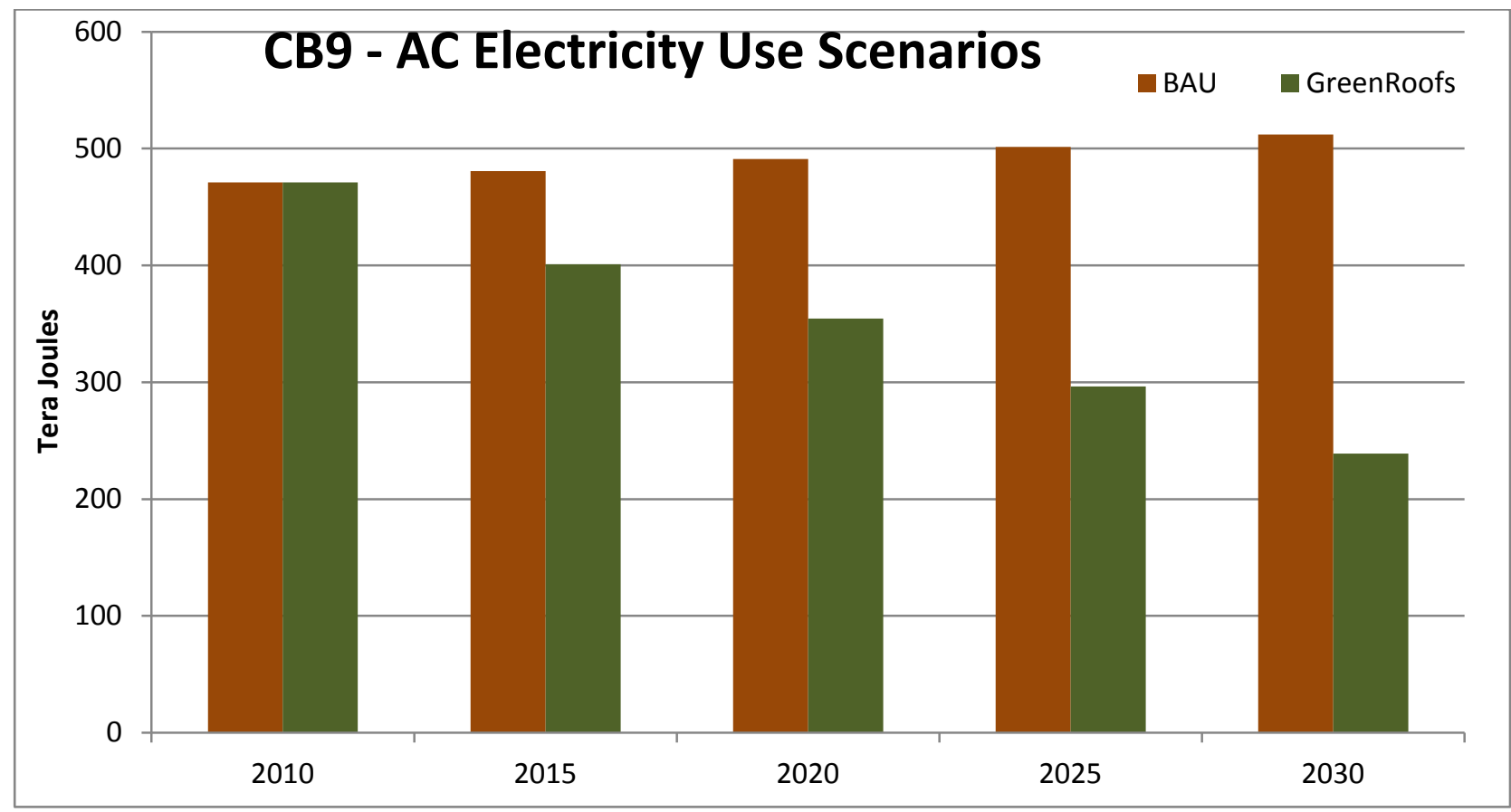

Figure 14: CB9 AC Electricity Use Comparison in BAU and Green Roofs

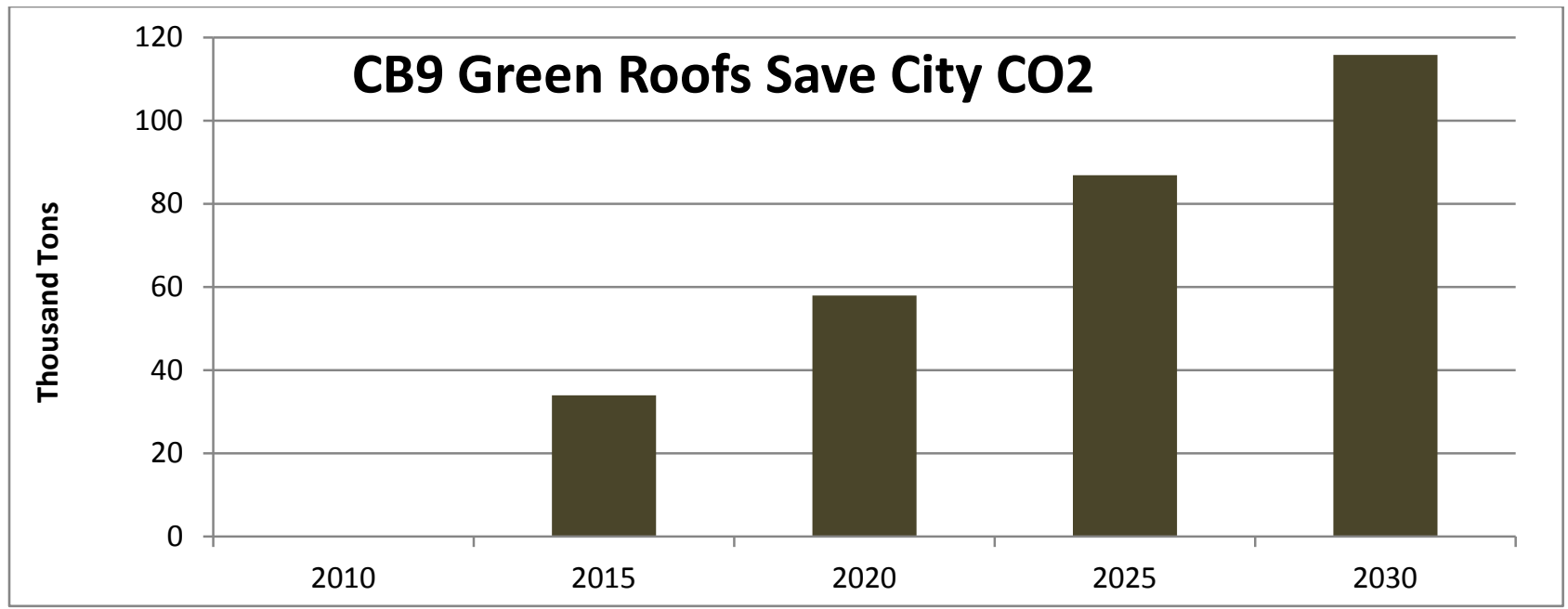

Figure 15: NYC CO2 Emissions Avoided by Deploying Green Roofs in CB9 


\section{CASE STUDY II: BROOKLYN COMMUNITY BOARD 6}

Brooklyn Community Board 6 (CB6) has a number of features which make it an attractive site for a second evaluation study. Brooklyn Community Board 6 is made up of a range of neighborhoods spanning the socio-economic spectrum. Despite the economic and ethnic diversity of the district, land use patterns in all neighborhoods are fairly consistent. The New York City Planning board map below shows over $50 \%$ of land use goes to 1- \& 2-family and multifamily dwellings. A closer look at building types using NYC Planning board PLUTO data verifies this conclusion.

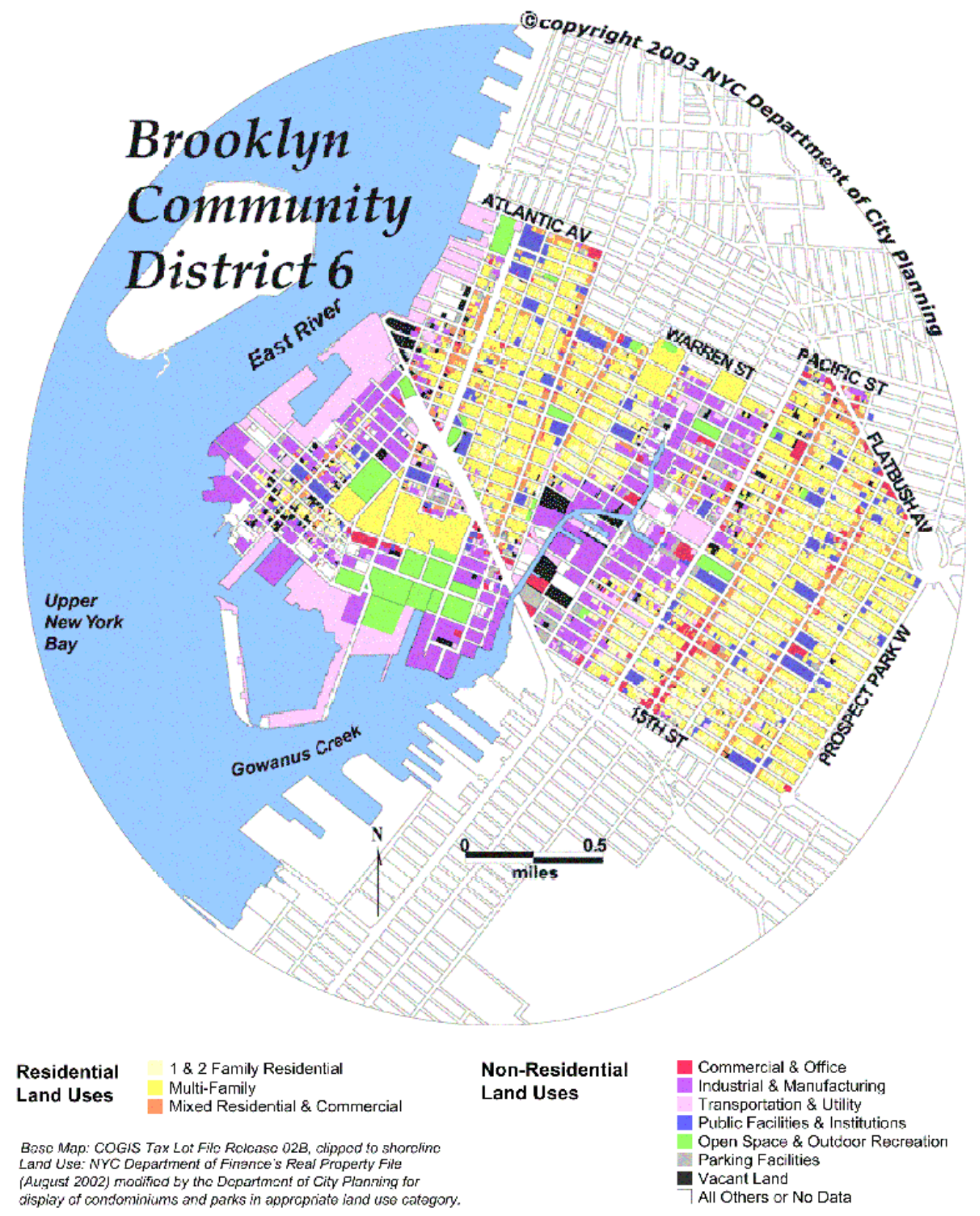

Figure 16: Brooklyn Demographics and Electricity Use 
The neighborhoods of Columbia Heights, Gowanus and Red Hook line the Gowanus canal, a famous and highly politicized superfund site. CB6 is also part of one of Con Edison's Solar Empowerment Zones, providing special incentives for the installation of rooftop PV. Finally, while CB6 is does not have the largest area of impervious ground surfaces or treeless blocks in the city, it is home to several large NYC Housing Authority facilities that have less vegetation and are hotter than adjacent older and in some cases more affluent neighborhoods. CB6 also has a very active and well organized planning board that aggressively engages on community livability issues. Recently CB6 board members conducted a tour of the in-district public housing complexes to gather information on livability both within the structures and on the grounds.

CB6 members and the public agencies and utilities that serve them are working to balance priorities on a number of different fronts. Often it is difficult to integrate competing concerns into the decision making process. The issues of air quality, street temperature and heat stress are seldom part of the discussion. Modeling energy use and land use against the metric of livability could inform the public debate on a range of issues facing not only CB6 but Community planning boards across the City.

Table 3: Building Composition in CB6

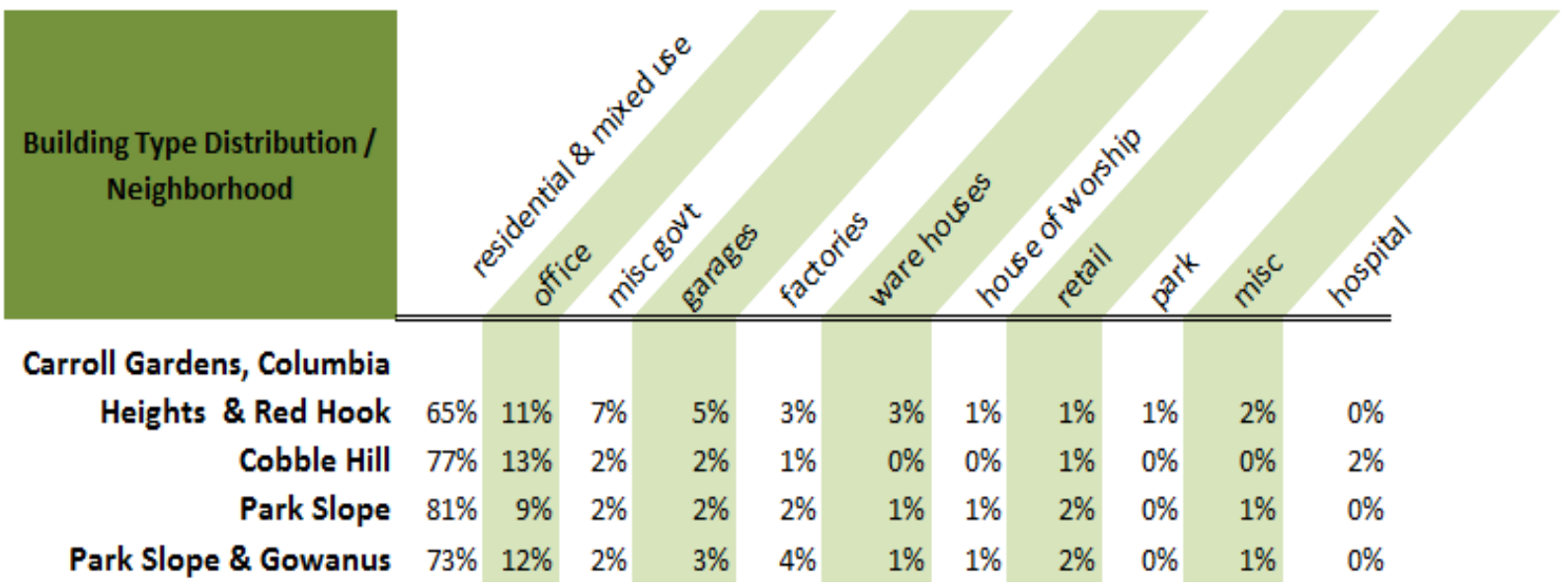

Table 3 shows that from $65 \%$ to over $80 \%$ of buildings in CB6 neighborhoods can be classified as residential. Even the neighborhoods of Columbia Heights, Gowanus and Red Hook that are zoned for light industry have a preponderance of residential buildings. Based on the high percentage of residential buildings, electric usage in CB6 will be driven by residential consumption patterns. 


\subsection{CB6 Building Electricity Consumption}

Based on the work of Howard et al, energy consumption for all blocks in CB6 has been extracted. The table below shows electric energy use aggregated by zip code as a neighborhood indicator. The neighborhood of Park Slope consumes the largest portion of energy annually.

Table 4: Electricity Use in CB6

\begin{tabular}{|c|c|}
\hline Brooklyn Commur & $\begin{array}{l}\text { Board } 6 \text { Electric Use by } \\
\text { Code }\end{array}$ \\
\hline Neighborhoods & Aggregate Electricity \\
\hline \& Zip Codes & Use $\left(10^{\wedge} 3 \mathrm{Kwh}\right)$ (Howard et al) \\
\hline Carroll Gardens, Colum & \\
\hline Hts \& Red Hook & 166,902 \\
\hline 0 & 731 \\
\hline 11231 & 165,056 \\
\hline 11232 & 1,115 \\
\hline Cobble Hill & 56,824 \\
\hline 0 & 1,839 \\
\hline 11201 & 54,985 \\
\hline Park Slope & 210,228 \\
\hline 11215 & 204,314 \\
\hline 11238 & 5,914 \\
\hline Park Slope \& Gowanus & 82,224 \\
\hline 11217 & 82,224 \\
\hline (blank) & 46,180 \\
\hline 0 & 46,180 \\
\hline Grand Total & 562,358 \\
\hline
\end{tabular}

While load curves for CB6 specifically are not available for privacy and security reasons, generic load curves are available. Load curves below are generic load curves for residential energy use.

Hauser et al generated residential load curves based on the Stuttgart residential pool segmented by income and at home energy use patterns. The load curve above is for affluent "conservative" energy users. This segment appears to have the highest per capita energy use of the segments examined in this paper. It is worth noting that in much of Germany people traditionally go home for lunch. This is particularly true for the older more "conservative" population, hence the bump in energy use around 12 noon. The largest energy consumption in the Hauser study takes place during the evening with a peak between 8 and 10 in the evening. ${ }^{8}$

\footnotetext{
${ }^{8}$ NYS data on total residential hour by hour load is currently unavailable. When the current NYSISO baseline load study is completed we will be able to validate our findings against published New York State data. Data from the German city of Stuttgart and province of Sao Paulo, Brasil were used to create as climactic and Socio-Cultural
} 
The affluent conservative curve is shown here as a potential stand in for the affluent energy users of the Park Slope neighborhood in Community Board 6.

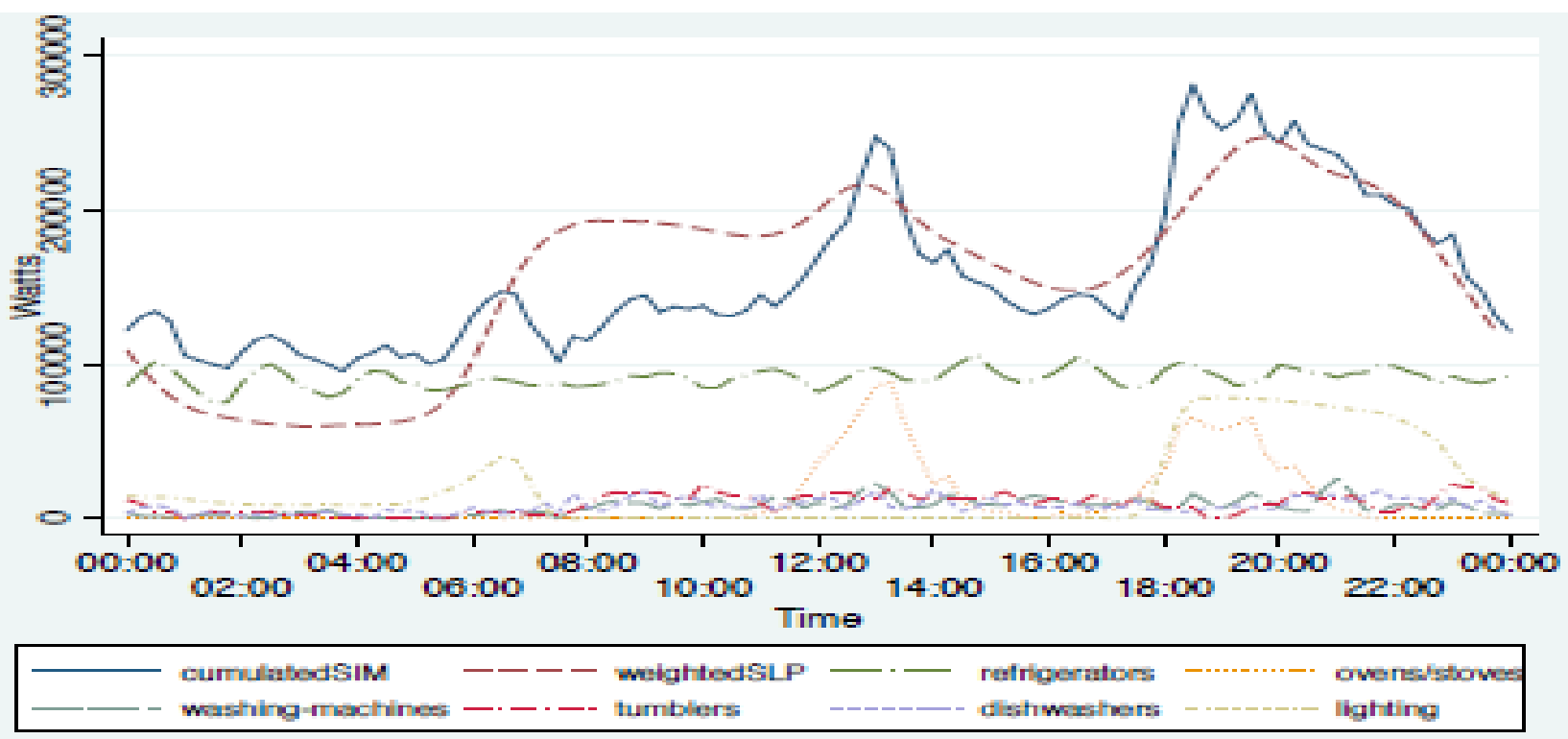

Hauser et al

Figure 17: Residential Load Curves for Stuttgart

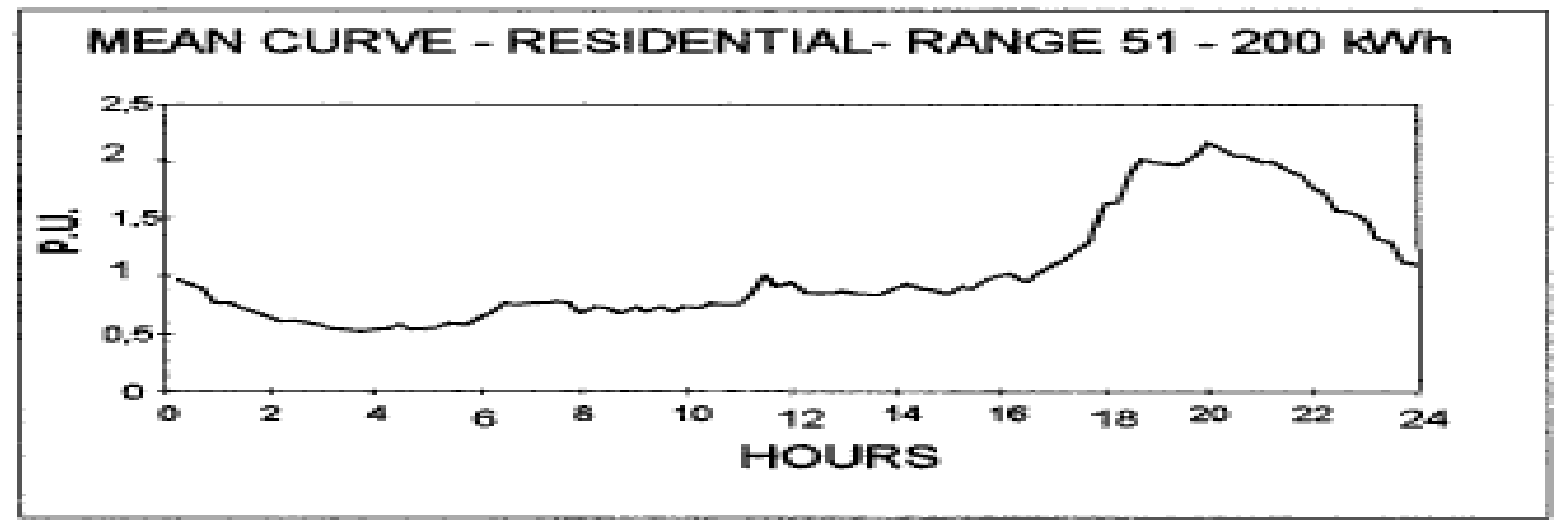

Jardini et al,2000 EEE TRANSACTONS ON PONER DELIVERY, VOL. 15, N0. 1, JANUARY 2000

Figure 18: Residential Load Curves for Sao Paulo

Jardini et al assembled load curves for the residential and commercial sectors in Sao Paulo State in Brazil. The residential sector was segmented into ranges of electrical consumption. The 51$200 \mathrm{kWh} /$ month sectors are contain the peak of the frequency distribution bell curve. The temperature in Sao Paulo State ranges from 50 to 95 degrees Fahrenheit. It seems reasonable 
that this residential load curve is applicable to NYC May through September cooling period. Hourly energy use data is expensive to collect. Individual household energy use in isolation does not have significant impact on the grid, an entire high rise building or a block of 1 to 2 family homes however can be influential. Because residential load curves are not widely available it will be assumed that CB6 neighborhood power use follows the night peaking profile assembled above by Jardini et al.

\subsection{MARKAL Analysis for Buildings Electricity in CB6}

In considering the results of the modeling analysis, it is most useful to focus on the differences between the scenarios representing the conditions with (Baseline Case + ) and without (Baseline Case ) the additional technologies, policies and measures selected for the study than on the absolute numerical results for any scenario. This approach minimizes the significance of these uncertainties on the impact of alternative scenarios measured against the Baseline Case developed here. Figure 19 shows buildings energy demands for various uses for Community Board 6 (CB6), as modeled in MARKAL.

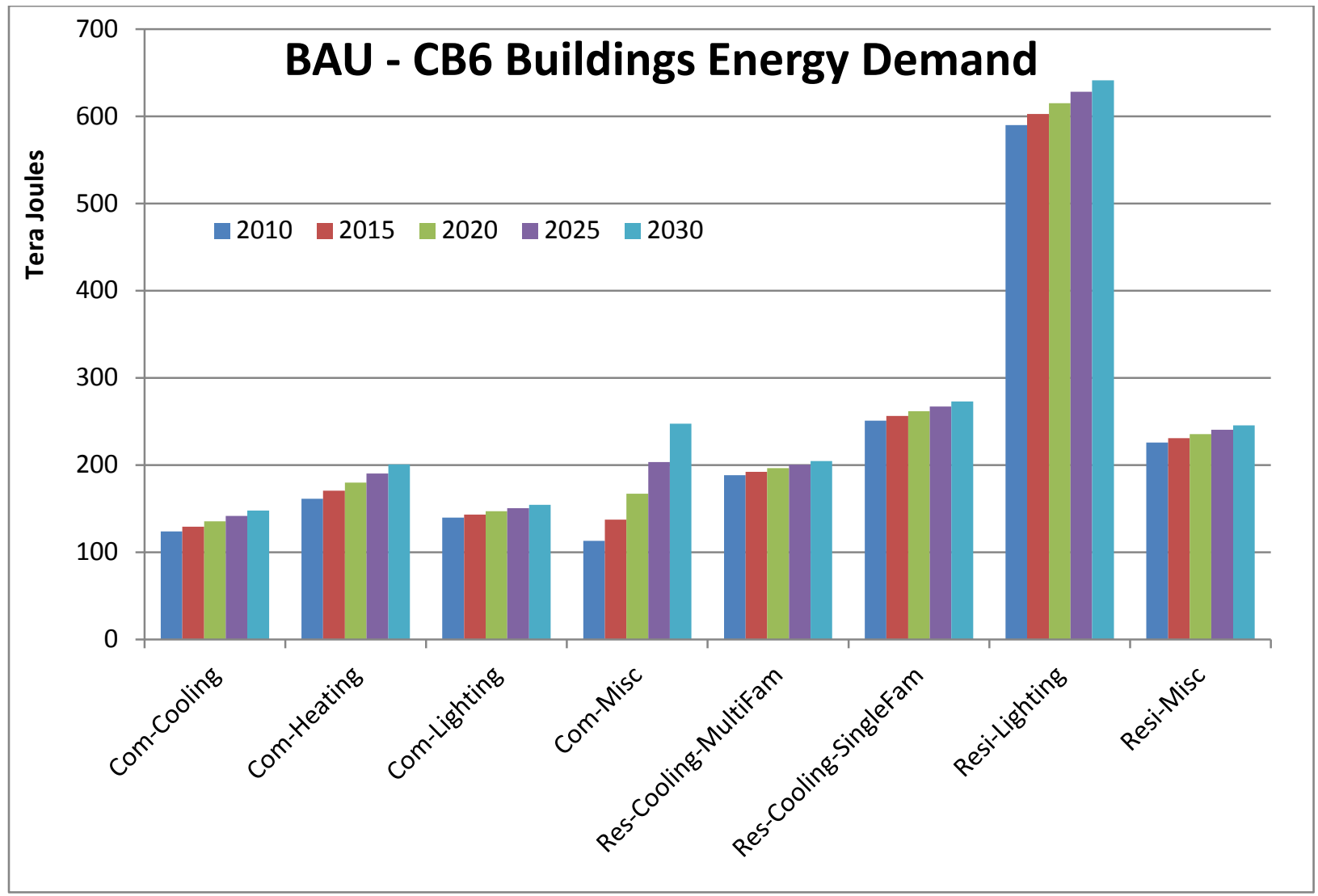

Figure 19: CB6 - Buildings Energy Demands in the Business as Usual (Base Line) Case in MARKAL 
The demand module of the model simulates the "business as usual" electricity demand by end-use in these building space types. Altered demand patterns attributable to efficiency programs (e.g., Energy Star), load management, conservation, and building codes are generated to compare with "business as usual", as highlighted in Figure 20.

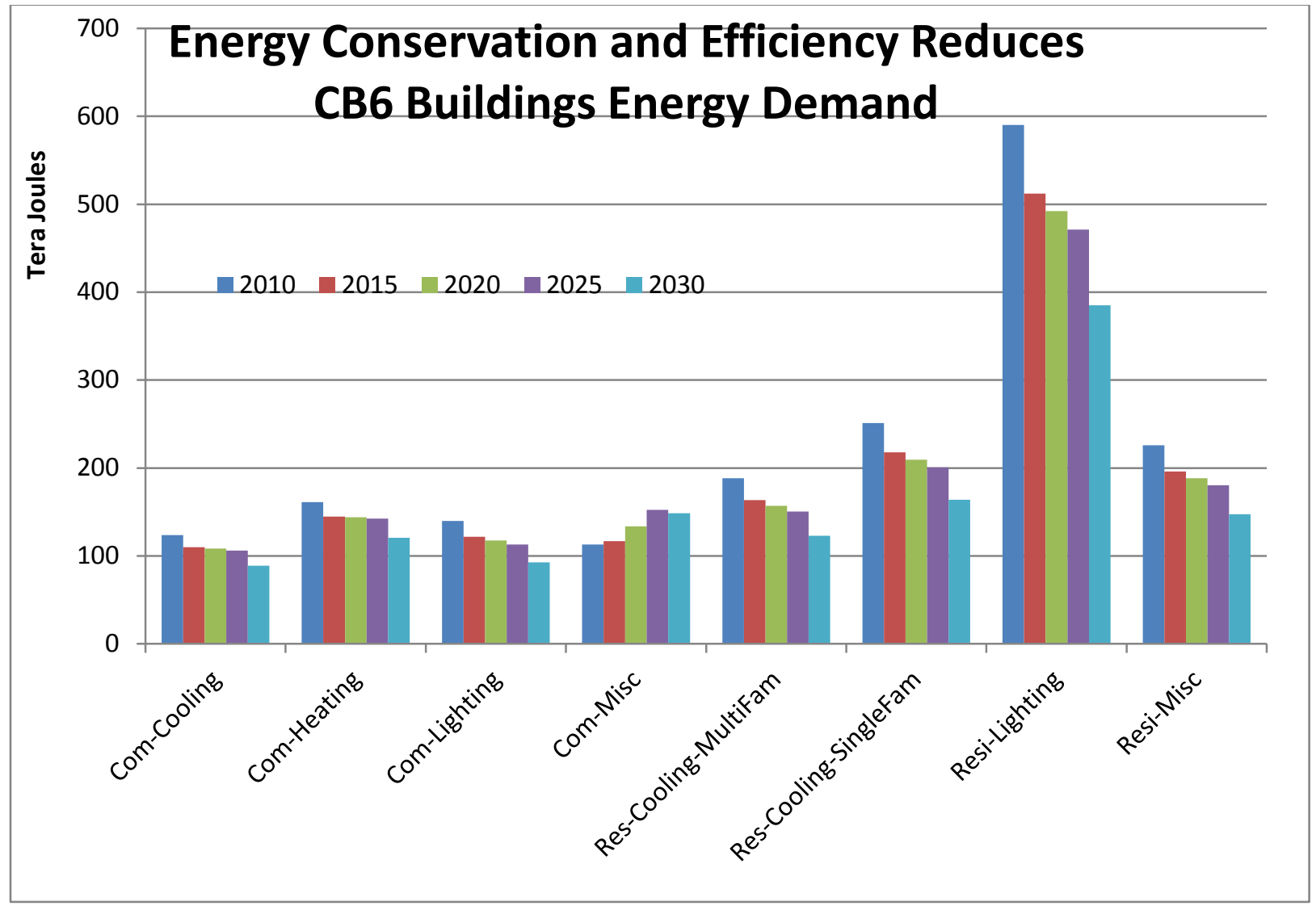

Figure 20: CB6 - Buildings Energy Demands with Energy Conservation and Efficient Technologies

Figure 21 showcases electric capacity needed by CB6 case study in two scenarios 1) Business as Usual/Base Case (BAU), and 2) Energy Conservation and Efficiency (EE). The reduction of electricity capacity indicates savings achieved through $E E$ measures. A significant drop in the year 2030 shows that a significant cost savings were achieved by avoiding a major investment in a power plant, which may have been invested to fulfill a retiring capacity from a power plant. 


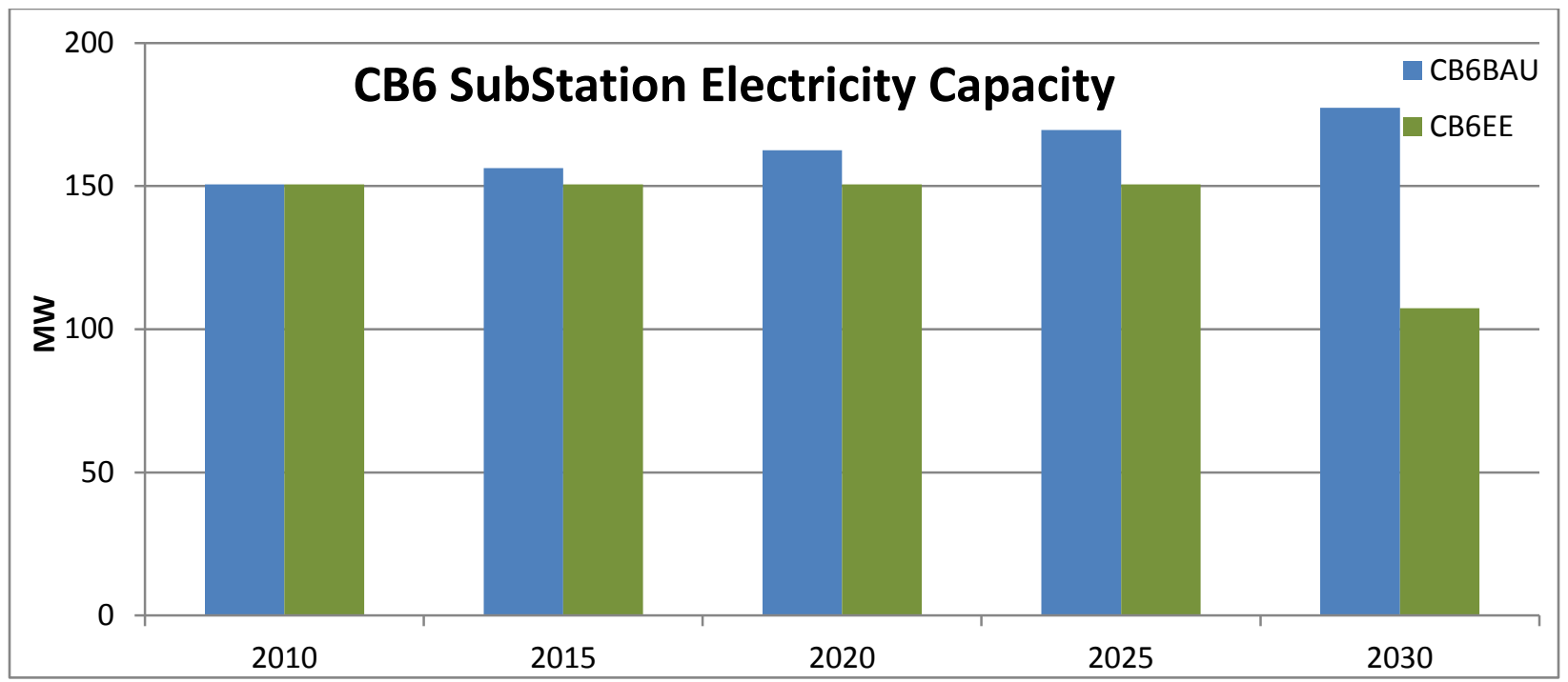

Figure 21: CB6 - Comparison of Electricity Capacity Needed in Two Scenarios

Preliminary results obtained from this portfolio approach indicate that Energy Star and UHI mitigation strategies, employed in tandem, can potentially lower aggregate demands, including air conditioning, to the tune of $25-40 \%$ for buildings. Figure 22 highlights projected electricity usage with and without energy efficiency investments.

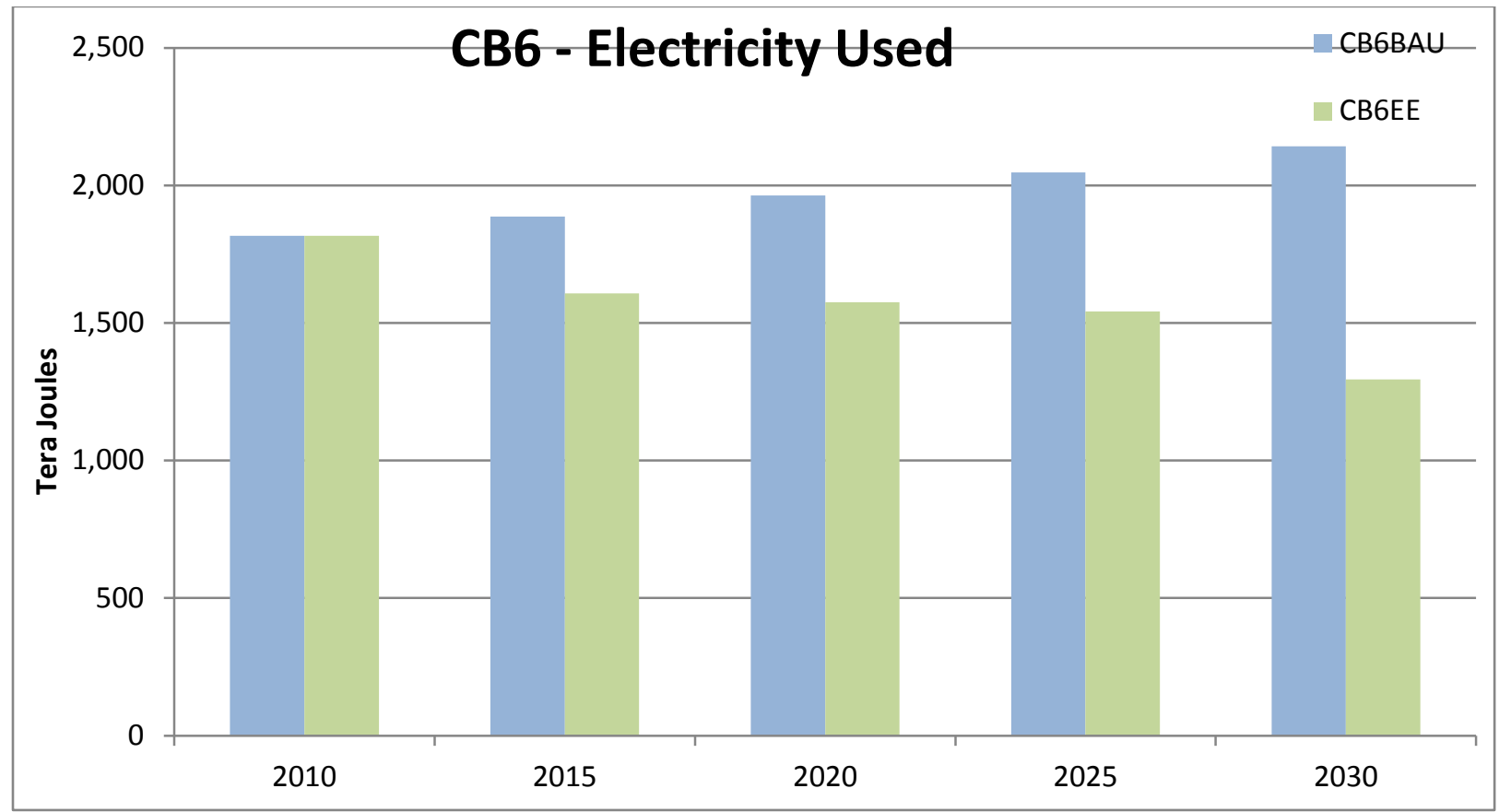

Figure 22: Significant Electricity Saved over time in EE Scenario for CB6 Case study 
The differences in the sub-station data (e.g. electricity, emissions) feed into the entire power network supply New York City to generate the impact of programs and measures on fuel use, greenhouse gas (GHG) and criteria pollutant emissions at specific power plants, as well as energy system costs and future expansion plans for electricity generation for the long-term (2010-2030), as outlined in figures 23 and 24.

As noted above, New York City's load pocket could be eased by reducing demand rather than installing new capacity. The extent to which energy conservation and efficiency can displace future expansion of new capacity is illustrated in figure 23.

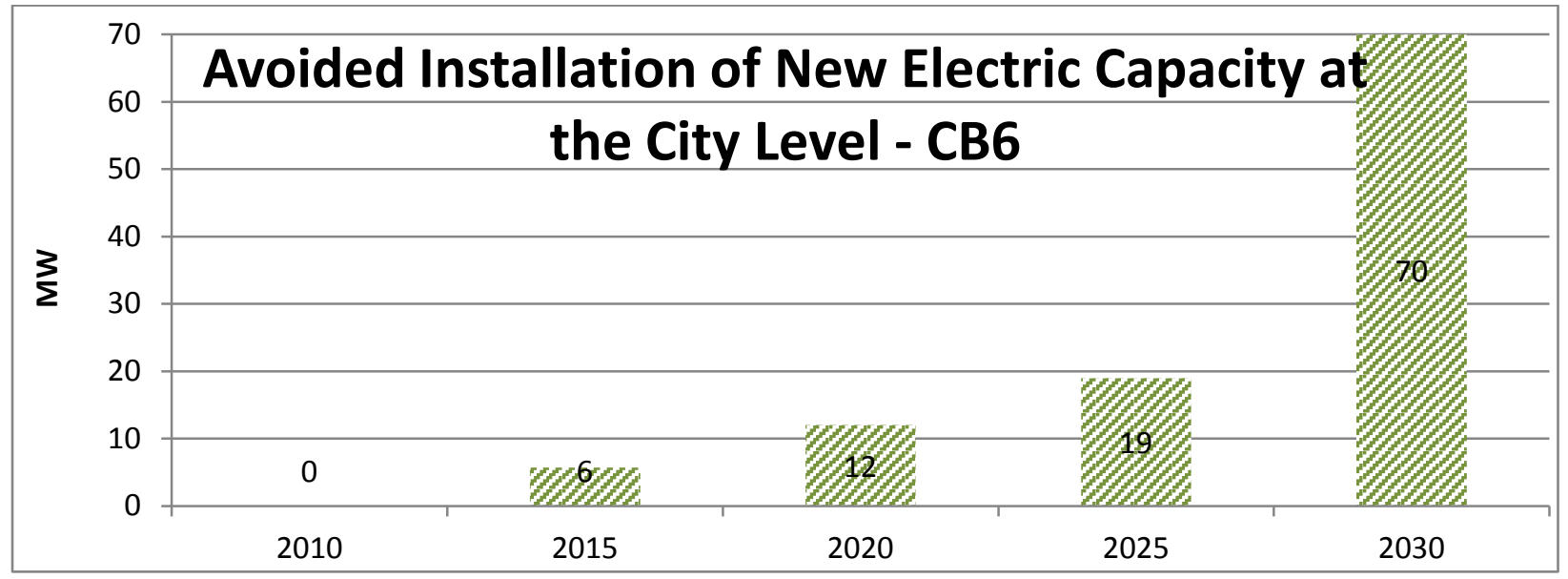

Figure 23: CB6 - Cumulative Avoided Installation of New Electric Capacity Compared to BAU Scenario

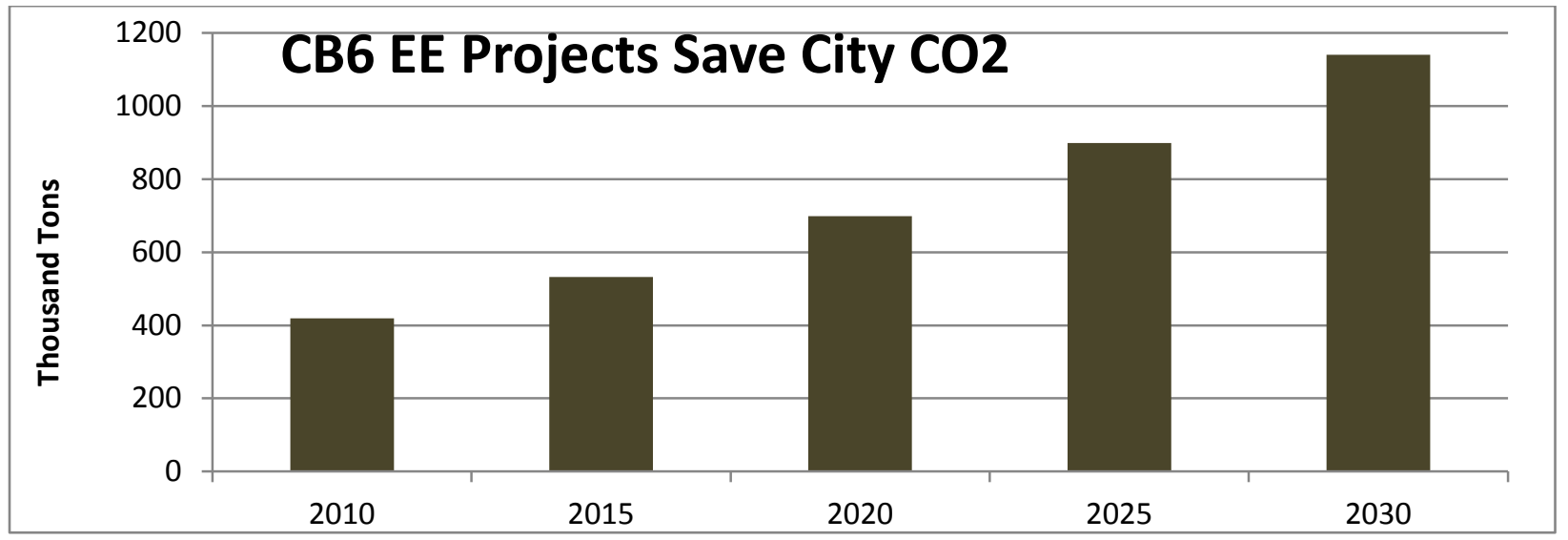

Figure 24: CB6 - Cumulative Avoided CO2 Emissions Compared to BAU Scenario 


\subsection{Potential for Savings with Green Roofs}

Examining the impact of vegetated urban surfaces and particularly green roofs on CB6 energy use, the table below shows the cooling load reduction potential associated with installing green roofs on all roofs in Brooklyn CB6.

Table 5: Electricity savings with Green Roofs

\begin{tabular}{|c|c|c|}
\hline \multicolumn{2}{|c|}{$\begin{array}{c}\text { Brooklyn CB6 Potential Green Roof Avoided } \\
\text { Cooling Load Reduction (kWh) }\end{array}$} & \\
\hline $\begin{array}{r}100 \% \text { green roof } A C \\
\text { reduction }\end{array}$ & $336,832,143$ & $\begin{array}{l}\text { In the CB6 assessment, } \\
\text { May-Sept avoided } \\
\text { cooling is used because }\end{array}$ \\
\hline $\begin{array}{l}75 \% \text { green roof } A C \text { reduction } \\
50 \% \text { green roof } A C \text { reduction }\end{array}$ & $\begin{array}{l}252,624,107 \\
168,416,072\end{array}$ & $\begin{array}{l}\text { May-Sept heat gain is } \\
\text { most attributable to heat } \\
\text { gain thru roofs }\end{array}$ \\
\hline
\end{tabular}

Green roof associated cooling however is most effective during the mid day hours between 9 am and $4 \mathrm{pm}$. The residential load curves above identify peak residential loads occurring just as green roof associated cooling is losing efficacy. The time period for $60 \%$ or greater of total heat transfer reduction is marked in the figure below.

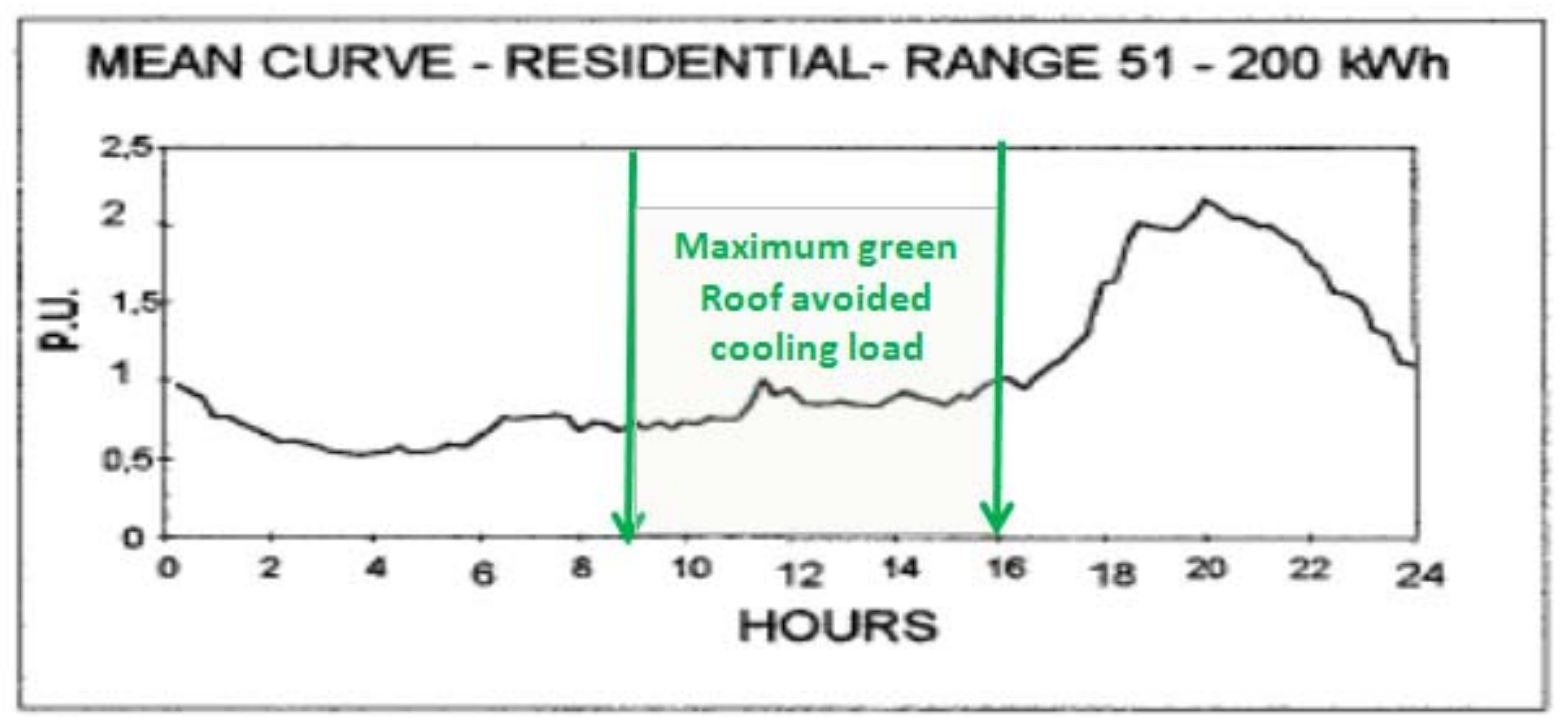

Figure 25: Residential Potential for Heat Transfer Reduction 
We can assume that the load curves of Park Slope and Cobble Hill that are $81 \%$ and $77 \%$ residential respectively look much like the residential load curves for Stuttgart and Sao Paulo. If this assumption is correct, then opportunities for green roof associated cooling in the leafy, affluent and middle-class neighborhoods of Park Slope and Cobble Hill are small. In the mostly treeless, mixed-use neighborhoods of Gowanus, Columbia Heights and Red Hook however, load curves may take a different shape and there may be more opportunities for green roof cooling load reduction. The table below shows potential cooling load reductions associated with these mixed-use middle- to low-income neighborhoods.

Table 6: Avoided Cooling Load with Green Roofs

\begin{tabular}{lr|r|c|}
\multicolumn{1}{c|}{$\begin{array}{c}\text { CB6 Mixed Use } \\
\text { Neighborhoods }\end{array}$} & $\begin{array}{l}\text { Aggregate } \\
\text { Electricity Use } \\
\text { (10^3 Kwh) } \\
\text { (Howard et al) }\end{array}$ & $\begin{array}{c}\text { avoided cooling load } \\
\text { potential from green } \\
\text { roofs on 50\% of } \\
\text { neighborhood roof } \\
\text { area(10^3 kWh) }\end{array}$ & $\begin{array}{c}\text { Percent of } \\
\text { Total Energy } \\
\text { Use }\end{array}$ \\
\hline $\begin{array}{l}\text { Carroll Gardens, } \\
\text { Columbia Heights \& }\end{array}$ & 166,902 \\
$\begin{array}{l}\text { Red Hook } \\
\text { Park Slope \& }\end{array}$ & 82,224 & 53,239 & $32 \%$ \\
Gowanus & & 29,594 & $36 \%$ \\
\hline
\end{tabular}

Both Gowanus and Red Hook are home to large public housing projects. These neighborhoods are also criss-crossed by several heavily used highways, the Gowanus expressway and the BQE. Gowanus, Columbia Heights and Red Hook may benefit from vegetated building and street surfaces across a broad range of livability issues including ambient temperature/heat alerts and air quality/air quality alerts. It is recommended that further research on residential loads in low-income residential neighborhoods and public housing accompany assessment of overall cooling effects of vegetative surfaces in largely un-vegetated urban spaces.

Green Roofs and vegetated urban surfaces can also limit or store urban street runoff. Gaffin et al estimate that green roofs can retain as much as 10 gallons of storm water annually per square foot of vegetated roof.

Figures 26 and 27 highlight cumulative energy and emissions savings in the MARKAL analysis for deploying Green Roofs. 


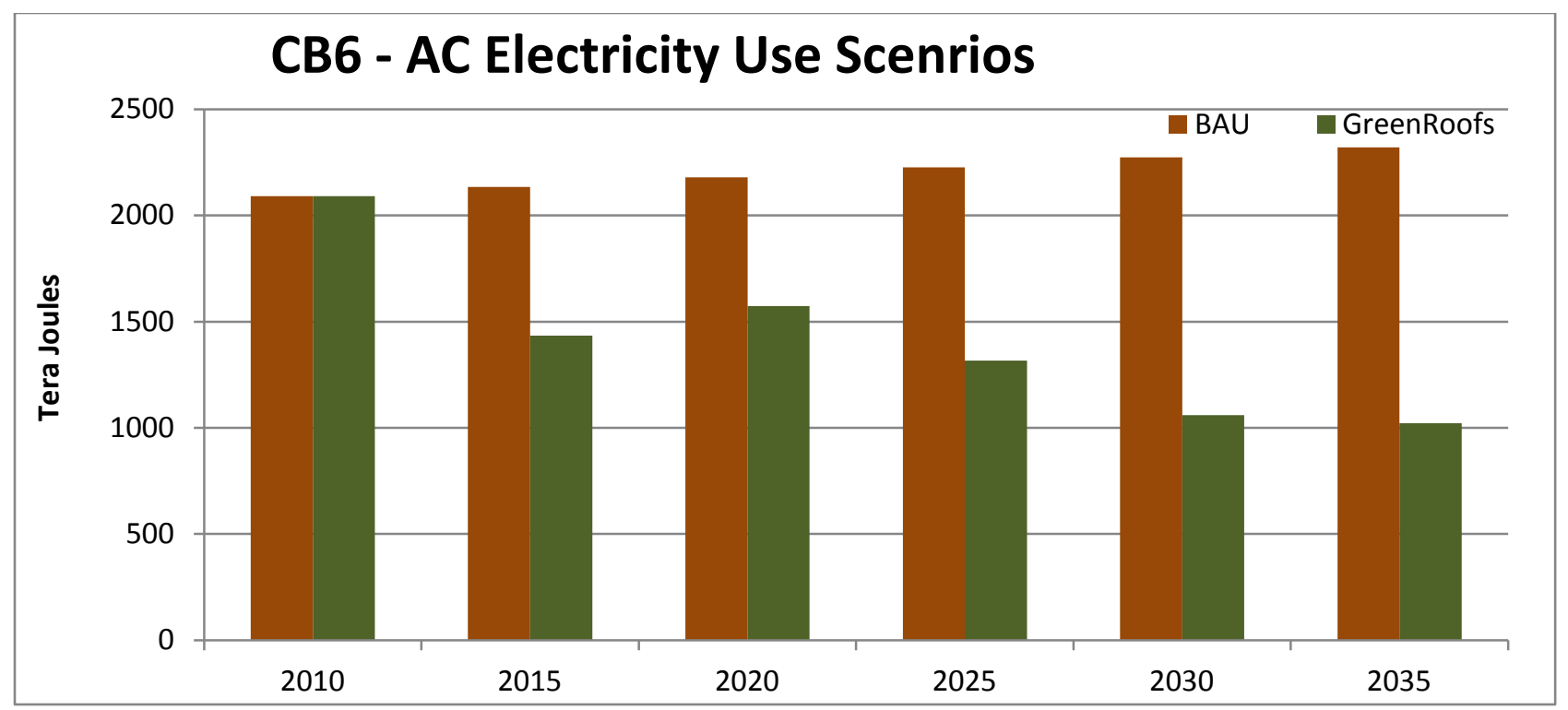

Figure 26: CB6 AC Electricity Use Comparison in BAU and Green Roofs

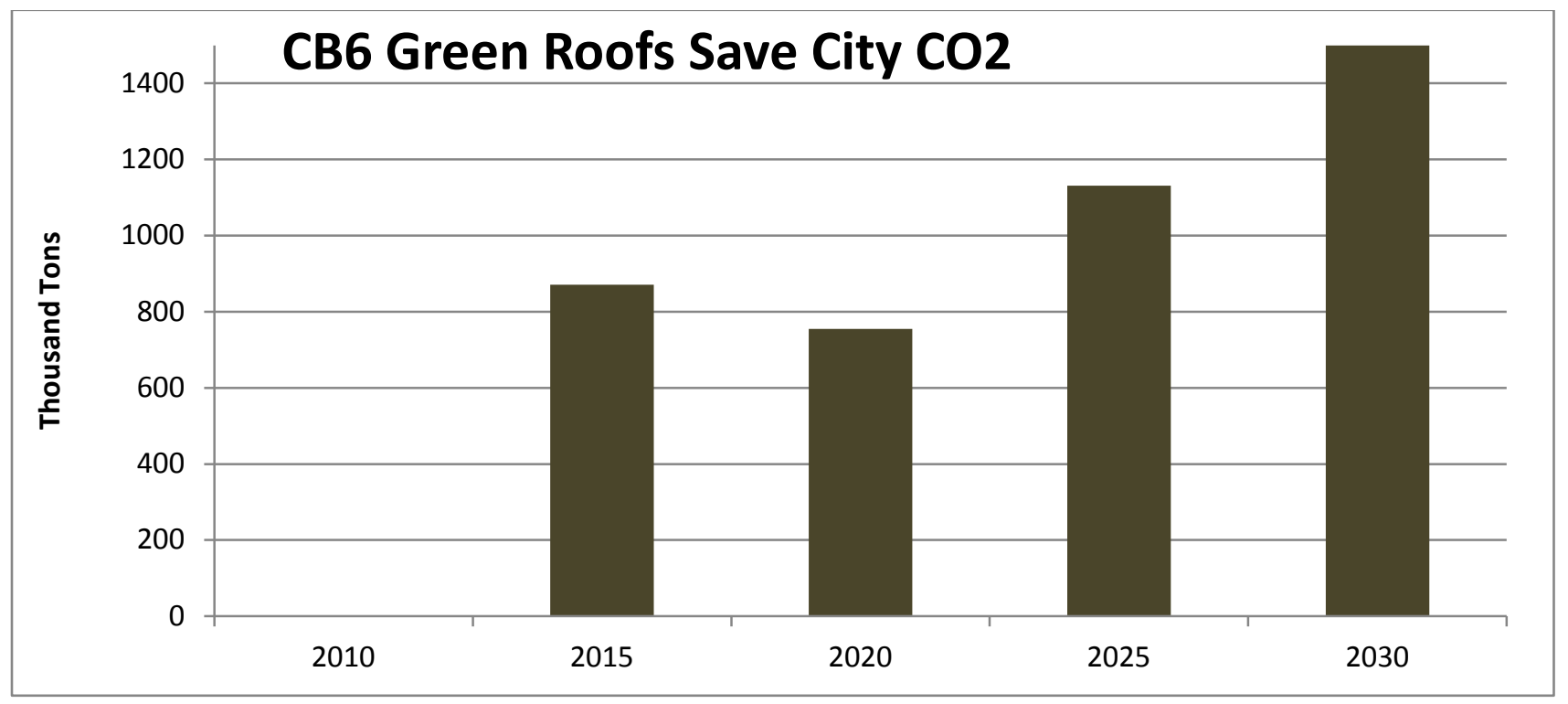

Figure 27: Cumulative NYC CO2 Emissions Saved by Deploying Green Roofs in CB6 


\subsection{Potential for Water Savings with Green Roofs}

Table 7 below shows the potential impact of green roof-associated storm water retention on treatment plants, receiving waters and the electrical grid.

Table 7: Storm Water Retention on Green Roofs

\begin{tabular}{|c|c|c|}
\hline \multicolumn{3}{|c|}{ Potential Green Roof Storm Water Retention in Brooklyn CB6 Neighborhoods } \\
\hline $2.95 \times 10^{6}$ & \multicolumn{2}{|c|}{$\mathrm{ft}^{2}$ of available roof - Using $50 \% \mathrm{NYC}$ PLUTO floor area to estimate useable green roof space } \\
\hline 10.2 & \multicolumn{2}{|c|}{$\mathrm{gal} / \mathrm{ft}^{2} / \mathrm{yr}$ storm water captured by green roofs -Gaffin et al 2010} \\
\hline 30.1 & \multicolumn{2}{|c|}{ million gallons of Storm Flow avoided annually } \\
\hline & \multicolumn{2}{|l|}{ compared to } \\
\hline 27 & \multicolumn{2}{|c|}{ Billion Gallons of storm water discharged to NYC waterways annually } \\
\hline & \multicolumn{2}{|c|}{ http://www.riverkeeper.org/campaigns/stop-polluters/sewage-contamination/cso/ } \\
\hline 44 & \multicolumn{2}{|c|}{$\mathrm{mWh}$ avoided annual storm water treatment energy use (CBECS-2007 median energy for wastewater treatment) } \\
\hline \multirow{6}{*}{$\begin{array}{l}10^{6} \text { gallons avoided } \\
\text { storm flow annually } \\
\text { in CB6 } \\
\text { Neighborhoods }\end{array}$} & Carroll Gdns, & Park Slope \\
\hline & Colmb Hgts Cobble Hill Park Slope & $\&$ \\
\hline & $\&$ Red Hook & Gowanus \\
\hline & 13.16 & 5.29 \\
\hline & \multicolumn{2}{|l|}{ compared to } \\
\hline & \multicolumn{2}{|c|}{$374 \times 10^{6}$ gallons of storm water discharged through the Gowanus canal annually } \\
\hline
\end{tabular}

Installation of green roofs in these neighborhoods could contribute to reduction of storm water flow and improvements of surface water quality in the canal. Further research into the potential for storm water management in these neighborhoods using vegetative building and street surfaces could yield an additional bonus for wastewater system relief. 


\section{Conclusions and directions for future research}

The first decade of the 21st century is now complete. Across the political spectrum, awareness is rising that concepts and institutions that served to broaden and enhance society have run their course and must be retooled. This awareness is particularly acute as NYC Community Planning Boards struggle with the conventional issues of social equity in housing, public services and environmental health. With adaptation to climate change raising additional and incremental challenges, planning boards are locked in a radically different struggle. A new theory and a set of implementation tools are needed. These tools must allow the boards to be proactive in networking the previous long standing issues with the new emerging issues - for an example the nexus between electricity needs, substation and grid bottlenecks, investing in new central power plants, criteria and greenhouse gas pollution and local health.

\section{Project Delivers Measurable Results for Pollution Prevention}

NYC-MARKAL's neighborhood-scale energy modeling tools are designed to enable local neighborhood planners to understand the impacts of alternative energy and environmental policy options. This project provided a clear and simplified methodology for incorporating distributed savings offered by very effective local solutions like energy conservation, improving energy efficiency by utilizing advanced technologies/appliances, green roofs and other strategies for two neighborhoods CB6 and CB9 by exemplifying their benefits at the substation level and upscaling these benefits to the city level savings by measurable matrix like 'avoided installed capacity for additional central power plants' and resulting 'savings in criteria pollutants and greenhouse gas emissions'.

For an example, air-conditioning load for the CCNY campus and CB9 were estimated using the NYC Office of Long Term Planning and Sustainability (OLTPS) and Howard et al 2012 (Figure 9 and Table 2) or for CB6 (Table 4 and Figure 19). The demand module of the model simulates the "business as usual" electricity demand by end-use in these building space types. Altered demand patterns attributable to efficiency programs (e.g., Energy Star), load management, conservation, and building codes are generated to compare with "business as usual", as highlighted in Figure 20. Preliminary results obtained from this portfolio approach indicate that Energy Star and UHI mitigation strategies, employed in tandem, can potentially lower aggregate demands, including air conditioning, to the tune of $25-40 \%$ for buildings. Figure 22 highlights projected electricity usage with and without energy efficiency investments. The differences in the sub-station data (e.g. electricity, Figure 21) feed into the entire power network supply New York City to generate the impact of programs and measures on fuel use, greenhouse gas (GHG) and criteria pollutant emissions at specific power plants, as well as energy system costs and future expansion plans for electricity generation for the long-term (2010-2030), as outlined in Figures 23 and 24. A significant drop in the year 2030 shows that substantial savings were achieved by avoiding a major investment in a power plant, which may 
have been invested to fulfill a retiring capacity from a power plant. Thus, New York City's load pocket could be eased by reducing demand rather than installing new capacity. The extent to which energy conservation and efficiency can displace future expansion of new capacity is illustrated in Figure 23.

This research could be further refined in the future by obtaining data from New York City Local Law 84. Local Law 84 is a city mandate that requires buildings with over 50,000 square feet to submit to an annual energy and water benchmarking. (See Henderson, 2011; Mayor's Office of Long-Term Planning and Sustainability, 2012.) The data could be utilized to identify spatial patterns of how the city uses its energy. This refined data in conjunction with the MARKAL tool would be ideal to further improve the future results of these types of studies. In 2013, Local Law 84 is expected to be released to the public.

\section{Outreach and Stakeholder Engagement}

NYC-MARKAL's neighborhood-scale energy modeling outlines clear strategy and matrix for targeted outreach to stakeholders (Table 8 identifies potential stakeholders with whom we should engage in the next phase of this study.). We recommend that these tools be made available to Community Planning Boards (CPBs) in the neighborhoods surrounding the CUNY campuses in which the pilot campuses reside. As a follow-up we plan to reach out to targeted representatives from the CPBs to connect them with student and faculty researchers who can work on neighborhood databases that will, ultimately, support the CPBs in energy planning, project development and implementation, which also facilitates outreach to the City developmental agencies like Mayor's Office of Long-term Planning and Sustainability.

The 59 CPBs in New York City are local advisory bodies that actively participate in a wide range of local issues, particularly those that affect land use and zoning and the delivery of local services. As this project focuses on "town-gown" interactions between selected CUNY campuses and their adjacent neighborhoods, we will develop ties with the Community Planning Boards and key CPB committees (such as Land Use and Zoning, Health, and Environment). The relationships established between the Community Planning Boards in this report and CUNY will continue. The ultimate goal is to have the potential of energy efficiency in the building stock of interest within these Planning Boards realized thereby providing specific measurable results. As a modeling project this report served to establish relationships and validate a methodology. Implementation is the next phase. 
Table 8. Stakeholders for Neighborhood-scale Energy Projects

\begin{tabular}{|c|c|c|}
\hline Sector & Agency & Stakeholder \\
\hline US Government & USEPA & Alex Peck, Ed Linky \\
\hline \multirow[t]{4}{*}{ New York State } & NYSERDA & Liz Hanna, Peter Savio \\
\hline & New York PSC & $\begin{array}{l}\text { Thomas Dvorsky (Director, office of Electric, } \\
\text { Gas and Water); Floyd Barwig (Director, } \\
\text { Office of Energy Efficiency and the } \\
\text { Environment }\end{array}$ \\
\hline & NY Power Authority & Guy Sliker \\
\hline & $\begin{array}{l}\text { NY Dormitory } \\
\text { Authority }\end{array}$ & Michael Stabulas (Director, CUNY Programs) \\
\hline \multirow[t]{4}{*}{ New York City } & $\begin{array}{l}\text { NYC Energy } \\
\text { Efficiency Corp. }\end{array}$ & $\begin{array}{l}\text { Christopher Diamond (Director, Engineering } \\
\text { and Technical Analysis) }\end{array}$ \\
\hline & $\begin{array}{l}\text { Community Planning } \\
\text { Boards }\end{array}$ & $\begin{array}{l}\text { Eutha Prince (District Manager, Manhattan } \\
\text { Community Board 9); Craig Hammerman } \\
\text { (District Manager, Brooklyn Community } \\
\text { Board 6) }\end{array}$ \\
\hline & NY City Council & $\begin{array}{l}\text { Members, Environmental Protection and } \\
\text { Community Development Committees }\end{array}$ \\
\hline & CUNY & $\begin{array}{l}\text { Tria Case (CUNY Sustainability Director); } \\
\text { Arthur Fasolino (CUNY Associate Chief } \\
\text { Engineer) }\end{array}$ \\
\hline \multirow[t]{2}{*}{ Electric Utilities } & Consolidated Edison & $\begin{array}{l}\text { Rebecca Craft (Director, Energy Efficiency } \\
\text { Group) }\end{array}$ \\
\hline & NYISO & Arthur Maniaci \\
\hline
\end{tabular}

We recommend that an initial focus of such partnerships should be the issues connecting energy use, environmental sustainability, public health, and environmental justice. This will set the stage for active student-CUNY-community communication and ease the process 
for collaboration by bringing together local stakeholders in a relationship to foster simpler communication and collaboration.

The neighborhood-scale application of MARKAL, used to advance a community-campus partnership, can enable stakeholders to identify areas of mutual advantage in considering new approaches to land use regulation for energy and environmental issues. One key example is that of urban heat island mitigation in a particular community. Low carbon is not the relevant metric for buildings but low thermal impact of both the building and the site, perhaps enhanced by a purpose-constructed urban canopy. Initially to the developer, this looks like a Zero Sum exercise, with the social benefits being offset by the very real private costs incurred. But a "Win-Win" approach through MARKAL allows in a fully transparent process for each stakeholder to discern metrically how a vegetative canopy can enhance site design, reduce electric load at the substation and reduce air emissions on the grid with attendant improvements in human health. The MARKAL model at community scale is a precision "Non Zero-Sum" or "Win-Win" tool, which quantifies costs and benefits to former Zero-Sum Stakeholders. Thus these new Win-Win Stakeholders proactively tackle the new challenges posed by climate change to the community.

This project has developed tools and frameworks for CUNY and CPBs to evaluate new building construction, major renovation projects, and facilities operations in terms of their energy and environmental impacts at multiple spatial scales and fulfill the needs of the Mayor's Sustainability Plan. We recommend that an urban-scale MARKAL model be extended to look at the energy and environmental impacts of selected campuses within the CUNY system, other campuses, neighborhoods and CPBs. This approach would enable these stakeholders to more effectively understand and act upon its role in pollution prevention and local electric reliability as well as its own energy efficiency and energy budget management needs. This could facilitate efforts for these stakeholders to achieve their goals of becoming a civic leader in more effective decision-making about sustainable energy use and environmental impacts.

\section{References}

Agyeman, J., Bullard, R.D., and Evans, B. (2002). Exploring the Nexus: Bringing Together Sustainability, Environmental Justice, and Equity. Space and Polity, 6 (1): 77-90.

Baker-Minkel, K., Moody, J., and Kieser, W. (2004). Town and Gown. Economic Development Journal: 7-15. 
USA. Department of Energy. Scientific and Technical Information. Estimates of U.S. Commercial

Building Electricity Intensity Trends: Issues Related to End-Use and Supply Surveys. By D. B.

Belzer. Pacific Northwest National Laboratory., Sept. 2009. Web.

<http://www.pnl.gov/main/publications/external/technical_reports/PNNL-16820.pdf>.

Bromley, R. (2006. On and Off Campus: Colleges and Universities as Local Stakeholders. Planning, Practice, and Research, 21(1): 1-24.

Campus Compact. (2007). Available at: www.compact.org

Cosmi, C., Macchiato, M.,Mangiamele, L.,Marmo, G., Pietrapertosa, F. and Salvia, M.(2003). Environmental and economic effects of renewable energy sources use on a local case study, Energy Policy 31: 443-457.

Gaffin, S. R., Rosenzweig, C., Eichenbaum-Pikser, J., Khanbilvardi, R. and Susca, T., 2010. “A Temperature and Seasonal Energy Analysis of Green, White, and Black Roofs" Columbia University, Center for Climate Systems Research. New York

Gaffin, S. R., C. Rosenzweig, and R. Kahnbilvardi. "Stormwater Retention for a Modular Green Roof Using Energy Balance Data." Columbia University January (2011): n. pag. Print.

Hamstead, M.P. and M.S. Quinn (2005). Sustainable Community Development and Ecological Economics: Theoretical Convergence and Practical Implications. Local Environment, 10(2): 141158.

Hauser, W., J. Evora, and E. Kremers. "MODELLING LIFESTYLE ASPECTS INFLUENCING THE RESIDENTIAL LOAD CURVE." ISBN: 978-0-9564944-4-3 / ISBN: 978-0-9564944-5-0 (CD). Proc. of Proceedings 26th European Conference on Modelling and. N.p., n.d. Web.

Henderson, A., 2011. "The Greener, Greater Buildings of New York City." In David J. Hess, ed., Urban Sustainability Programs: Case Studies, www.davidjhess.org, 59-64

Hess, D., and L. Winner (2007). Enhancing Justice and Sustainability at the Local Level: Affordable Policies for Urban Governments. Local Environment, 12(4): 379-395.

Howard, B., L. Parshall, J. Thompson, S. Hammer, J. Dickenson, and V. Modi. "Spatial Distribution of Urban Building Energy Consumption by End Use." Energy and Buildings 2012th ser. 45 (2012): 141-52. Print.

Jacobson, M.Z. (2007). On the Causal Link Between Carbon Dioxide and Air Pollution Mortality. Geophysical Research Letters, 35. 
Linky, E., Bhatt, V., and Lee, J. (2008). Analytical tools shaping the next generation of carbon regulation and trading: The New York metropolitan area case studies, Sustainable Development Law and Policy, 8(2): 51-60.

Liu, K., and B. Bass. "Performance of Green Roof Systems." RCl-Cool Roof 2005_KL 050322.doc. National Research Council Canada, 05 Mar. 2005. Web. <http://irc.nrc-cnrc.gc.ca/ircpubs>.

MapPLUTO $^{\mathrm{TM}}$ @ 2003-2012. NYC Department of City Planning. All rights reserved.

Markandya, A. \& Wilkinson, P. (2007). Electricity Generation and Health. The Lancet, 370: 979990.

Martin, L.L., Smith, H., and Phillips, W. (2005). Bridging 'Town \& Gown' Through Innovative University-Community Partnerships. The Innovation Journal: The Public Sector Innovation Journal, 10(2): 1-16.

Mayor's Office of Long-Term Planning and Sustainability, 2012. New York City Local Law 84 Benchmarking Report: A Greener, Greater New York. Downloaded 12/31/2012 from http://www.nyc.gov/html/gbee/downloads/pdf/nyc_Il84_benchmarking_report_2012.pdf

McMichael, A..J. (2000). The Urban Environment and Health in a World of Increasing Globalization: Issues for Developing Countries. Bulletin of The World Health Organization, 78(9).

New York City. (2007). PlaNYC 2030: A Greener, Greater New York. Available from: http://www.nyc.gov/html/planyc2030/html/downloads/download.shtml

New York City Department of Health and Mental Hygiene. (2003). Asthma Facts, $2^{\text {nd }}$ Edition. Available at: http://www.nyc.gov/html/doh/downloads/pdf/asthma/facts.pdf

Parker, J. and P. Selman (1997). Working Toward Sustainable Communities in Canada. The London Journal of Canadian Studies, 13: 61-76.

Reardon, KM. (2006). Promoting Reciprocity within Community/University Development Partnerships: Lessons from the Field. Planning, Practice, \& Research, 21(1): 95-107.

Satterthwaite, D. (1997). Sustainable Cities or Cities that Contribute to Sustainable Development? Urban Studies, 34(10): 1667-1691.

Seebregts, A., Goldstein, G., Smekens, K. (2002). Energy/Environmental Modeling with the MARKAL Family of Models, Selected Papers of the International Conference on Operations Research OR 2001), Duisburg, September 3-5, 2001, Retrieved November 1, 2008, from http://www.uni-duisburg.de/or2001/pdf/Sek\%2002\%20-\%20Seebregts\%20Goldstein\%20Smekens.pdf 
Selman, P. and J. Parker (1999). Tales of Local Sustainability. Local Environment, 4(1): 47-60.

Sharp, L. (2002). Public Participation and Policy: unpacking connections in one UK Local Agenda 21. Local Environment, 7(1): 7-22.

Sinha, P. and S. Spiegel (2008). Greenhouse Gas (GHG) Inventory Program, prepared for City College of New York by O'Brien and Gere, Blue Bell, PA. Last downloaded on 1/3/2010 from http://acupcc.aashe.org/ghg-report.php?id=77.

Sonne, Jeff. "Evaluating Green Roof Energy Performance." ASHRAE Journal 2006th ser. 48.Feb (2006): n. pag. ASHRAE. Web. <www.ashrae.org>.

Vasi, I. (2007, September). Thinking Globally, Planning Nationally and Acting Locally: Nested Organizational Fields and the Adoption of Environmental Practices. Social Forces, 86(1): 113136.

Weinberg, A.S. (2002). The University: An Agent of Social Change? Qualitative Sociology, 25(2): 263-272.

Whitman, S., Good G., Donoghue, E.R., Benbow, N., Shou, W., \& Mou, S. (1997). Mortality in Chicago Attributed to the July 1995 Heat Wave. American Journal of Public Health, 87(9): 515518.

Wilkinson, P., Smith, K.R., Joffe, M., \& Haines, A. (2007). Energy and Health 1: A Global Perspective o Energy: Health Effects and Injustices. The Lancet. 370 (9591): 965-978.

http://www.nyc.gov/html/dcp/html/bytes/applbyte.

MapPLUTOTM @ 2003-2012. NYC Department of City Planning. All rights reserved.

http://www.nyc.gov/html/dep/html/dep projects/gowanus.shtml NYC DEP Waterbody/Watershed Facility Plan: Gowanus canal

http://www.riverkeeper.org/campaigns/stop-polluters/sewage-contamination/cso/

"Daily Load Profiles for Residential, Commercial and Industrial Low Voltage Consumers." Free Reference Manager and PDF Organizer. N.p., n.d. Web. 17 Sept. 2012. $<$ http://www.mendeley.com/research/daily-load-profiles-residential-commercial-industriallow-voltage-consumers/>. 